\title{
Regulation of Sox8 through IncRNA Mrhl mediated chromatin looping in mouse spermatogonia
}

\author{
Bhavana Kayyar a, Anjhana C. Ravikkumar a, Utsa Bhaduri a *, and M.R.S Rao a\# \\ a - Molecular Biology and Genetics Unit, Jawaharlal Nehru Center for Advanced Scientific \\ Research, India \\ *- Present address:Department of Life Sciences, University of Trieste, Italy, and EU Horizon 2020. \\ TRIM-NET Innovative Training Network (ITN) of Marie Sklodowska-Curie Actions (MSCA).
}

Running Head: Mrhl lncRNA regulates Sox8 through chromatin looping (52 characters with spaces)

\#Correspondence to Prof. M.R.S. Rao, mrsrao@jncasr.ac.in

E. mail ID of all the other authors: Bhavana Kayyar: bhavanakayyar@gmail.com,

Anjhana C. Ravikkumar: anjhana.cr@gmail.com, Utsa Bhaduri: UTSA.BHADURI@phd.units.it

Abstract- 197 words
Main text - 6073 words
Materials and Methods - 1732 words 


\section{Abstract:}

2 Sox 8 is a developmentally important transcription factor that plays an important role in sex mainte-

3 nance and fertility of adult mice. In the B-type spermatogonial cells, Sox 8 is regulated by the

4 lncRNA $M r h l$ in a p68-dependant manner under the control of the Wnt signalling pathway. The

5 downregulation of $M r h l$ leads to the meiotic commitment of the spermatogonial cells in a Sox8-

6 dependant manner. While the molecular players involved in the regulation of transcription at the

7 Sox 8 promoter have been worked out, our current study points to the involvement of the architec-

8 tural proteins CTCF and cohesin in mediating a chromatin loop that brings the Sox 8 promoter in

9 contact with a silencer element present within the gene body in the presence of lncRNA Mrhl con-

10 comitant with transcriptional repression. Further, lncRNA Mrhl interacts with the Sox 8 locus

11 through the formation of a DNA:DNA:RNA triplex which is necessary for the recruitment of PRC2

12 to the locus. The downregulation of lncRNA $M r h l$ results in the promoter-silencer loop giving way

13 to a promoter-enhancer loop. This active transcription associated chromatin loop is mediated by

14 YY1 and brings the promoter in contact with the enhancer present downstream of the gene.

\section{Introduction}

Sox8 is a developmentally important transcription factor that is critical for the maintenance of adult male fertility. Sox 8 knockout mice become progressively infertile because of age-related degeneration of spermatogenesis (O'Bryan et al, 2008). The Sertoli specific deletion of Sox9 (another essential transcription factor involved in mammalian sex determination) in Sox8 null embryonic mice results in failure to achieve the first wave of spermatogenesis (Barrionuevo et al., 2010). The deletion of both Sox8 and Sox9 in adult sertoli cells results in testis to ovarian genetic reprogramming (Barrionuevo et al, 2016) while Sox 8 alone is sufficient for ovarian to testicular genetic reprogramming in the absence of R-spondin1 (Richardson et al, 2020)

Regulation of gene expression in mammals is a complex interplay of intricately controlled events. While decades of work has brought about some understanding of these regulatory events including the role of transcriptional factors, the role of proximal and distal regulatory elements, the long noncoding RNAs are the latest entrants to this hotbed of research. It is emerging that lncRNAs are inextricably involved in every step of gene regulation.

Mrhl lncRNA is a $2.4 \mathrm{~kb}$ long mono-exonic transcript that is transcribed from an independent transcription unit within the 15 th intron of the phkb gene in mice (Nishant et al, 2004). This chromatinbound lncRNA regulates the expression of multiple genes in the mouse spermatogonial cells in a Wnt signalling dependent manner. Sox 8 is one of the three genes that the lncRNA regulates by binding to their promoters in a p68-dependent manner (Akhade et al, 2014). 
Our group has previously deciphered the gene regulatory mechanism in play at the promoter of Sox8 in mouse spermatogonial cells. Mrhl binds at the Sox 8 promoter $\sim 140$ bp upstream of the Transcription start Site (TSS) and the Mad-Max transcription factors along with the co-repressors Sin3a and HDAC1 are also bound at the Sox8 promoter close to the $M r h l$ binding site in the presence of $M r h l$. Wnt signalling-mediated transcriptional regulation of Sox8 involves substantial changes in the chromatin dynamics of the promoter. There is a concomitant transcriptional activation of Sox 8 expression with downregulation of $M r h l$ and associated changes include the Mad-Max complex being replaced by the Myc-Max transcription factors and increased levels of H3K4me3 and H3K9ac histone modifications and decreased levels of H3K27me3 modification at this locus. Simultaneously, beta-catenin binds at the Wnt responsive element present at the promoter (Kataruka, S. et al., 2017). Activation of the Wnt signalling cascade in Gc1-spg cells results in their meiotic commitment marked by the increase in the levels of pre-meiotic and meiotic markers (Akhade, V.S. et al., 2016) including that of the master regulator, Stra8, in a Sox8-dependent manner.

While chromatin associated lncRNAs interact with DNA through protein bridges, an alternative mode of interaction is by directly binding to DNA. The potential of lncRNAs to form hybrid structures such as DNA:DNA:RNA triplexes to directly interact with DNA have been explored in the past decade. LncRNAs including Meg3, KHPS1 and PARTICLE have been reported to form triplex structures at genomic regions having AG rich motifs (Mondal et al, 2015, Postepska-Igielska et al, 2015, O'Leary et al, 2015). In addition to acting as tethers, triplexes have been shown to act as platforms for the recruitment of DNA methyltransferase complex DNMT3b by pRNA at the $r D N A$ locus or the polycomb repressive complex PRC2 by lncRNAs MEG3 and Fendrr (Schmitz et al, 2010, Mondal et al, 2015, Grote and Herrmann, 2013) and thereby influence the expression of genes in the vicinity.

Recent advances indicate a role for lncRNAs in bringing together distant gene regulatory elements in $3 \mathrm{D}$ space to regulate gene expression. CTCF, the master architectural protein in mammalian cells, mediates interactions between distant genomic elements, resulting in context-dependent functional outcomes. The cohesin complex is essential in stabilising these CTCF mediated 3D contacts while various proteins such as Ying-Yang1 (YY1), DDX5/p68 and CHD8 among others supplement CTCF's role in genome organization (Ong and Corces, 2014). CTCF can bind to lncRNAs through its RNA-binding domain (Saldaña-Meyer et al, 2014) and the deletion of the RNA-binding domain within CTCF compromises its ability to homodimerise - an essential ability to enable chromatin looping (Saldaña-Meyer et al, 2019). The lncRNA CCAT1-L associates with CTCF to bring the MYC promoter in contact with the enhancer $515 \mathrm{~Kb}$ away from where it is transcribed itself 
71 (Xiang et al, 2014). The role of the CTCF-cohesin complex along with lncRNA SRA and the 72 DEAD-box RNA helicase DDX5/p68 in maintaining imprinting at the H19/Igf 2 has been extensive73 ly studied (Yao et al, 2010).

74

In the present study, we show that $M r h l$, in association with the nuclear organizing factors CTCF, cohesin and YY1, mediates the formation of dynamic chromatin loops at the locus. In addition, Mrhl forms a triplex at the Sox 8 promoter and contributes to the regulation of gene expression through the triplex mediated recruitment of PRC2.

\section{Results:}

\section{Mrhl forms a triplex at the Sox8 locus}

Sox 8 is transcribed from a bidirectional promoter on chromosome 17. The binding of $M r h l$ at the promoter of Sox8, 140bp upstream of the TSS, is dependent on DDX5/p68 (Fig 1A). Since multiple chromatin associated lncRNAs interact with DNA through the formation of DNA:DNA:RNA triple helix structures, it was of interest to investigate if $M r h l$ lncRNA also interacts with the Sox 8 locus through the formation of triplex.

Majority of the lncRNA:DNA triplexes have been reported to form at AG- rich regions. The region $\sim 1.2 \mathrm{~kb}$ upstream of the Sox8 TSS harbours $\sim 50$ AG-repeats and is a prime candidate for triplex formation. Initial in silico predictive analysis was done using the Triplexator tool. Triplex Forming Oligo (TFO)-Triplex Target Sites (TTS) pairs with a score of 10 and above (Table 1) were considered for further experimentation. The TTS sequences were found to be overlapping within a $33 \mathrm{bp}$ DNA sequence between the regions -1224 and -1257 of the Sox 8 promoter while 2 sequences mapping to 2 distinct regions of Mrhl RNA, one mapping to the 5' end of the lncRNA and the other to the 3' end, were identified as TFO sequences. The 33nt region from the Sox8 locus was split between 3 DNA oligos for downstream experiments while 2 RNA oligos were generated, each mapping to the two different predicted regions.

EMSA was carried out to check for interaction between specific DNA and RNA oligonucleotides in vitro. A positive control TFO-TTS pair from within Meg3 lncRNA and its target TGFBR1 gene (Mondal et al, 2015) and a negative control TFO-TTS pair with no AG bias within the Sox8 locus and Mrhl RNA were included for EMSA. Of the 5 TFO-TTS pairs probed, 2 combinations with Mrhl TFO1 as the RNA oligo, TTS2 and TTS3, showed a mobility shift corresponding to the formation of triplex. Triplex reactions were additionally subjected to RNase $\mathrm{H}$ digestion, which specifically degrades DNA:RNA duplexes to rule out any shift in mobility arising due to this hybrid duplex, in addition to RNase A digestion controls. While both TTS-TFO pairs showed a decrease in 
106 the intensity of signal with RNaseA treatment, only one (Mrhl TFO1- TTS2) was resistant to RNase

$107 \mathrm{H}$ digestion (Fig 1B). Since the purine bases G and A participate in the formation of Hoogsteen

108 base pairing, the $\mathrm{G}$ bases were mutated to $\mathrm{C}$ in TTS2 to look for the effect on triplex formation. We

109 observed a loss in the mobility shift when the mutant oligos were used (Fig 1C). This pair was se-

110 lected as a probable triplex-forming region between $\mathrm{Mrhl}$ and the Sox 8 locus.

112 To validate the results from EMSA, Circular Dichroism spectra for the TFO-TTS pairs TTS2-TFO1

113 and TTS2-NC TFO were recorded. The spectra recorded for the test oligos showed characteristics

114 of a triplex with two minima- a strong negative peak at $210 \mathrm{~nm}$ and an additional negative peak at

$115240 \mathrm{~nm}$ (Fig 1E \& 1F). Artificial spectra were generated by plotting the sum of the individual spec-

116 tra for either TTS2 and TFO1 or TTS2 and NC TFO. When the artificial spectra were overlaid with

117 the spectra obtained from the triplex reactions, an overlap in the spectra for the control oligo was

118 observed but not for the specific TFO1 containing spectra indicating that the spectrum for the reac-

119 tion containing control oligo is due to individual components (Fig 1E\&F).

121 Further, the formation of triplex within the nucleus was investigated by using biotinylated TFO 1 or

122 control TFO as bait to pulldown associated chromatin. Compared to the control oligo, TFO 1 pull-

123 down fraction was significantly enriched for the Sox8 TTS2 containing locus but not for a control

124 region from the Beta-actin locus (Fig 1G). This enrichment was not significantly affected by

125 RNaseH digestion thereby confirming that the TFO from within $M r h l$ lncRNA interacts with the

126 Sox8 locus through the formation of a DNA:DNA:RNA triplex.

127

128

129

130

131

132

133

134

135

136

137

138

139

140

\section{Triplex formation regulates Sox8 expression through PRC2 recruitment}

Triplex formation by lncRNA can regulate genes present in its vicinity - either by activating or repressing gene expression. Specifically, triplex formation could act as a platform for the recruitment of DNMT3b which methylates the $\mathrm{CpG}$ island present in the vicinity, thereby leading to gene repression (Schmitz et al, 2010). Since the Sox 8 promoter and the TTS is located within a CpG island (supplementary Fig 2B), we wanted to investigate if lncRNA triplex formation leads to methylation of this $\mathrm{CpG}$ island to maintain Sox8 in the repressed state. The methylation status was investigated in the murine cell line Gc1-spg, derived from the B-type spermatogonia, a cell line in which the role of $M r h l$ lncRNA has been extensively characterised, in the absence and presence of the Wnt ligand. Under control conditions, $M r h l$ is actively expressed and maintains Sox 8 in the transcriptionally repressed state and activation of the Wnt signalling pathway results in the downregulation of $M r h l$ lncRNA which activates Sox8 expression (Akhade et al, 2014). To our surprise, no reduction in methylation levels was observed when $\operatorname{Sox} 8$ transcription was activated. These results were corrob- 
141

142

143

144

145

146

147

148

149

150

151

152

153

154

155

156

157

158

159

160

161

162

163

164

165

166

167

168

169

170

171

172

173

174

175

orated by the results of methylation levels in mice testes of 7-day old and 21-day old mice (Supplementary Fig 2D). Testes of P7 mice have a predominant population of spermatogonial cells (cells without activation of Wnt signalling) while testes of P21 mice have a predominant population of spermatocytes (with activation of Wnt signalling). Much of the results pertaining to Mrhl lncRNA and Sox 8 expression and regulation in control and Wnt-signalling activated cells are also reflected in P7 and P21 mice testes respectively (Akhade et al, 2014, Akhade et al, 2016, Kataruka et al, 2017).

We have shown earlier that Sox8 repression correlates with high levels of the repressive histone modification H3K27me3 in spermatogonia (Kataruka et al, 2017). So, we next checked for the presence of PRC2 at the promoter in the presence of $M r h l$ by performing ChIP for EZH2, a core subunit of PRC2 which enables PRC2- RNA interaction. The occupancy of Ezh2, which was observed under control conditions, was found to reduce upon activation of the Wnt signalling pathway in the Gc1-spg cells (Fig 2A).

Since multiple features including high GC-content of DNA, unique DNA conformations, presence of a guide lncRNA or the RNA:DNA:DNA triplex structure can recruit PRC2 to the target locus, we wanted to understand the contribution of the triplex formation by Mrhl lncRNA to the occupancy of PRC2 at the Sox 8 locus. To this end, we attempted to rescue Ezh2 occupancy by expressing Mrhl lncRNA containing either the Wild-type (WT) TFO or mutated TFO. While WT Mrhl lncRNA expressed in trans in the presence of the wnt cue resulted in the rescue of Ezh2 occupancy, mutant TFO did not have a similar effect (Fig. 2B). Therefore, we conclude that the formation of triplex by Mrhl lncRNA at the Sox 8 locus recruits PRC2 to the Sox 8 locus. Furthermore, we also looked at the ability of TFO mutant Mrhl to rescue Sox 8 transcript levels. WT Mrhl was able to rescue to expression of Sox 8 to the levels comparable to control conditions (Fig 2C). Interestingly, the TFO mutant was able to transcriptionally repress Sox 8 similar to WT Mrhl. This indicates that triplex formation, while required for PRC2 recruitment, is not necessary to maintain Sox 8 in the repressed state (Fig. 2C) and points to additional role for Mrhl lncRNA in repressing Sox 8 transcription.

\section{CTCF and cohesin bind at the Sox 8 locus in the presence of IncRNA Mrhl}

The p68-dependent gene repression of Sox 8 by $M r h l$ lncRNA is reminiscent of the role of lncRNA $S R A$ and $\mathrm{p} 68$ at the imprinted H19/Igf2 locus where the two molecules associate with architectural proteins CTCF and cohesin to silence Igf2 gene on the maternal allele (Yao et al, 2010). We looked for potential CTCF and cohesin binding sites at the Sox8 locus to check if a similar mechanism of 
176 gene repression was operating here. ENSEMBL database revealed that the transcription factor

177 CTCF binds at a binding site present in exon 3 of the Sox8 gene (Fig 3A). An inverse correlation

178 between Sox8 expression pattern and CTCF binding was observed across various tissues (supple-

179 mentary fig 2B; activity at the Sox8 gene locus is considered as an indication of Sox8 expression)

180 indicating that CTCF binding corresponds to the transcriptionally repressed state of the gene. The

181 cohesin complex, too, binds at this region along with CTCF (supplementary 4A). CTCF binding is

182 observed in those tissues in which $\mathrm{Mrhl}$ is expressed suggestive of cooperation between Mrhl and

183 CTCF in the regulation of Sox 8 in multiple tissues (supplementary 4B).

184

We then analysed publicly available ChIP-sequencing datasets to visualise the binding of the 2 architectural proteins at the Sox 8 locus in more detail. Due to the unavailability of required ChIP-seq datasets in spermatogonial cells, mouse embryonic stem cells and adult brain cortex were used as surrogate systems. Mrhl lncRNA is expressed in mESC while it isn't expressed in the adult brain cortex (Pal et al, 2021). The inverse relationship between Mrhl and Sox8 expression in these two tissues was confirmed by analysing publicly available RNA-seq datasets (Fig 3B\&C). ChIP-Seq analysis for CTCF, SMC1 subunit of cohesin, RNA Pol II and H3K4me3 to indicate transcriptional activity at the locus was carried out in these two surrogate systems. This confirmed the occupancy of CTCF within exon 3 of Sox 8 in mESC in which Sox 8 is not actively transcribed (low transcript levels in RNA seq and low relative levels of RNA polII at promoter and H3K4me3 at the locus).

The same was found to be true for cohesin (the presence of SMC1 has been considered as evidence of cohesin occupancy). Interestingly, an additional peak for both CTCF and cohesin was observed at the promoter of Sox8 very close to the $M r h l$ binding site (Fig 3D). Upon transcriptional activation (adult brain cortex) (higher transcript levels and relative occupancy of RNA polII at promoter and H3K4me3 at the locus), CTCF and cohesin occupancy were not observed at the promoter and the occupancy at exon3 was significantly reduced (Fig. 3E). This occupancy pattern was experimentally validated by performing ChIP for CTCF and Rad21 subunit of the cohesin complex in Gc1-spg cells without and with activation of the Wnt signalling pathway. A gene desert locus in chromosome 3 was chosen as a negative control for the ChIP-qPCR. To confirm that ChIP experiments were working, western blotting was carried out for the proteins (supplementary 4). The results from these experiments showed protein occupancy for both CTCF and $\operatorname{Rad} 21$ at both exon3 and Sox 8 promoter regions under control conditions. In the Wnt activated cells, CTCF and Rad21 binding at both positions in the Sox8 locus was significantly reduced (Fig3F,3G). We knew from previous p68 
211 inactivated conditions. This occupancy too reduced upon Mrhl downregulation by Wnt signalling

212 activation (Fig. $3 \mathrm{H}$ ).

214 To understand if the differential binding of these proteins at the Sox8 locus was dependent upon

$215 M r h l$ or was due to an indirect, downstream effect of the activation of the Wnt pathway, their occu216 pancy was investigated in cells in which $M r h l$ was depleted by RNAi. ChIP was carried out in cells 217 in which two different inducible lentiviral shRNA constructs targeting Mrhl or a non-target control 218 construct were integrated (Fig. 4A). Similar to what was observed under Wnt induced conditions, 219 occupancy of CTCF, Rad21 and p68, observed at both exon3 and promoter of Sox8 in cells with 220 non-target control, was depleted upon RNAi mediated $M r h l$ downregulation indicative of their $M r h l$ 221 IncRNA dependent occupancy at the Sox8 locus (Figs 4C, 4D \& 4E).

We also investigated the status of occupancy of these proteins in the testes of mice in an attempt to address the biological relevance of the participation of CTCF and cohesin in Sox 8 gene regulation. Results of ChIP carried out for CTCF, Rad21 and p68 in P7 and P21 mouse testes corroborated with the results from control GC1-spg and Wnt induced/ RNAi induced Mrhl downregulated cells respectively (Figs 4F, 4G \& 4H). The 3 proteins were found to be bound at the Sox 8 locus in the testes of 7-day old mice and a significant reduction in the occupancy was observed in 21-day old mice testes.

\section{YY1 binds at the Sox8 locus upon Mrhl downregulation}

232 CTCF and cohesin occupancy at the Sox8 promoter was not seen in ENSEMBL database. In silico 233 analysis using the Gene Promoter Miner tool was performed to look for probable interacting partners of CTCF that could be present at the Sox 8 promoter. The analysis of the promoter for transcription factor binding sites revealed the presence of a binding site for Ying-Yang 1 (YY1), a CTCF interacting transcription factor (Supplementary Fig 5A). Exon3 has characteristics of an enhancerblocker or a silencer element, a type of cis-regulatory element of a gene which contributes to tranthe promoter. If so, when not in the transcriptionally repressed state, the Sox 8 promoter is free to interact with an enhancer element. YY1 has been reported to bind at enhancers of genes and facilitate active transcription by enabling enhancer-promoter contact. As per the ENSEMBL database, two enhancer elements are present in the immediate vicinity of the Sox 8 gene, one upstream and one downstream of Sox8, and activity in both these elements correlated with transcriptional activity

244 of Sox8. In an attempt to identify if YY1 enables the active transcription of Sox 8 by binding to its 
mouse spermatogonial cells. Multiple tissue-specific enhancers have been reported to regulate the expression of the members of the SoxE group of transcription factors. Specifically, the expression of $\operatorname{Sox} 9$, another essential transcription factor for sex determination and maintenance of mammalian testis, is regulated by multiple testis-specific enhancers, either synergistically or redundantly (Gonen et al, 2018). An early attempt to identify enhancers for Sox8 identified 7 evolutionarily conserved regions in the vicinity of the gene with potential to act as enhancers. However, none of these elements acted as an enhancer in the embryonic gonad (Guth et al, 2010). Another study hinted at the presence of two regulatory elements downstream of the gene, specifically in cells of gonadal origin (Garcia-Moreno et al, 2019). Collating information from these different sources, we identified two regions downstream of $\operatorname{Sox} 8$, one $8 \mathrm{~kb}$ downstream and another on $14 \mathrm{~kb}$ downstream, as putative enhancers. Of these two regions, the element proximal to Sox 8 harbours one of the 7 evolutionarily conserved elements (E6).

We performed ChIP for the enhancer specific histone marks and for YY1 in Gc1-spg cells with and without activation of the Wnt signalling pathway to explore if (a) either one of the two putative elements gained enhancer specific histone modifications concomitant with Sox 8 transcriptional activation and (b) if YY1 could potentially be regulating Sox8 expression by binding to the enhancer. Both the putative enhancer as well as the gene promoter regions had a significant increase in the levels of H3K4me1 and H3K27ac marks upon Wnt induction (Figs 5A \& B). Additionally, increased occupancy of YY1 at both of these enhancers and at the gene promoter was observed with Wnt activation (Fig 5C). The same trend was also observed in the RNAi mediated Mrhl knockdown cells. While the levels of $\mathrm{H} 3 \mathrm{~K} 4 \mathrm{me} 1$ and $\mathrm{H} 3 \mathrm{~K} 27 \mathrm{ac}$ at both putative enhancer elements were low in cells with non-target control shRNA, the levels increase significantly in cells containing both Mrhl targeting shRNA (5D \& E). Similarly, the occupancy of YY1 increased significantly at both the elements as well as the promoter upon Mrhl depletion (Fig. 5F) Finally, these observations were found to be biologically relevant since the testes of 21-day old mice showed significantly higher levels of $\mathrm{H} 3 \mathrm{~K} 4 \mathrm{me} 1$ and $\mathrm{H} 3 \mathrm{~K} 27 \mathrm{ac}$ marks (Fig. 5G \& 5H) as well as the occupancy of YY1 (Fig. 5I) at both the enhancer regions as well as the promoter of Sox8 when compared to testes of 7-day old mice.

\section{Mrhl mediates a looping switch at the $\operatorname{Sox} 8$ locus}

Many of the proteins bound at the promoter of Sox8 including PRC2, p68, HDAC, Sin3a, and MAD-Max have been reported to interact with the proteins identified as bound within exon 3 of Sox8 including CTCF and cohesin. We reasoned that occupancy of proteins such as $\mathrm{p} 68$ and $\operatorname{Rad} 21$ was detected at both the promoter and exon 3 because this protein complex was bringing the pro- 
moter and exon 3 in contact with each other through looping of chromatin at the Sox8 locus. Silenc-

282

283

284

285

286

287

288

289

290

291

292

293

294

295

296

297

298

299

300

301

302

303

304

305

306

307

308

309

310

311

312

313

314

315

er elements have been reported to repress gene transcription in precisely this manner - by binding to transcriptional repressors such as $\mathrm{CTCF}$, contacting the gene promoter and preventing promoterenhancer interaction (Ogbourne \& Antalis, 1998). Additionally, we hypothesised that Mrhl downregulation resulted in the dissociation of the promoter- silencer contact freeing the promoter to come in contact with the downstream enhancer element.

To validate the hypothesis, we looked at the chromatin looping status in the presence and absence of lncRNA Mrhl through Chromosome Conformation Capture (3C). From 3C performed in Gc1spg cells with and without RNA knockdown, we observed that the Sox 8 promoter was indeed brought in contact with exon3 in a Mrhl dependent manner supporting our hypothesis. Interestingly, of the two enhancers identified downstream of $\operatorname{Sox} 8$, the interaction frequency between the promoter and the proximal enhancer (present $8 \mathrm{~kb}$ downstream of TSS) was found to be higher in Mrhl knockdown cells while there was no significant difference in the interaction frequency between the promoter and more distal enhancer (14kb downstream of TSS) upon Mrhl depletion, suggesting an enhancer function for the proximal element in the mouse spermatogonial cellvs (Fig 6)

\section{Discussion:}

A member of the SoxE group, Sox8 is essential for the maintenance of male fertility as Sox 8 null mice show progressive degeneration of spermatogenesis resulting in infertility (O'Bryan et al, 2008). Specifically, Sox 8 expression in Sertoli cells is essential for germ cell differentiation (Singh et al, 2009). Most of the previous studies have focussed on understanding the role of Sox 8 in Sertoli cells in mammalian testes. Studies from our group were the first to not only report the expression of Sox8 in spermatogenic cells but also explore the potential role of this transcription factor in meiotic commitment, likely via the master regulator of meiosis in spermatogenesis, Stra8 (Kojima et al, 2019). In this context, it was of importance to study the detailed molecular events during the regulation of Sox 8 by Mrhl lncRNA.

The formation of a DNA:DNA:RNA triplex is a mechanism of interaction that is common to many chromatin bound lncRNAs such as Meg3, PARTICLE, HOTAIR and KHPS1 (Mondal et al, 2015, O'Leary et al, 2015, Kalwa et al, 2016, Blank-Giwojna et al, 2019). In the current study, we show that Mrhl too interacts at the Sox 8 locus directly with the chromatin through the formation of DNA:DNA:RNA triplex. $M r h l$ lncRNA harbours multiple potential triplex forming regions within it. The in silico predictions for the Sox 8 locus suggested two different regions to have triplex forming potential - one mapping to the 5' end and another towards the 3' end. While the sequence towards the 5' end participates in triplex formation at the Sox8 locus in the Gc1-spg cells, it is possi- 
ble that the sequence towards the 3' end forms triplex in a different context. The predictions from Triplexator using different genomic regions such as Pou3f2, Runx2 or FoxP2 (Pal et al, 2021), show that other regions within $M r h l$ lncRNA, too, have the potential to form triplex. It is likely that $M r h l$ interacts at multiple other loci through the formation of DNA:DNA:RNA triplex through different TFOs present within it in a context dependent manner.

\section{$\mathrm{PRC2}$ in Sox8 gene regulation}

322

Many genes are repressed through methylation of $\mathrm{CpG}$ rich DNA at their promoters. Further, triplex formation by the ncRNA pRNA acts as a platform for the recruitment of the DNA methyltransferase DNMT3b at the rDNA promoter which goes on to methylate the DNA at the gene promoter, thereby repressing transcription (Schmitz et al, 2010). The presence of a $1.3 \mathrm{~kb}$ long $\mathrm{CpG}$ island encompassing the promoter of Sox 8 suggested s probable mechanism of gene repression through the methylation of this $\mathrm{CpG}$ island. However, no reduction in methylation levels was observed experimentally corresponding to Sox 8 activation in either the mouse spermatogonial cell line Gc1-spg upon Wnt induction or in 21-day old mouse testes suggesting that DNA methylation is not the mechanism of epigenetic repression of Sox8.

The presence of high levels of H3K27me3 repressive histone mark in the Sox 8 transcriptional repressed state (Kataruka et al, 2017) was indicative of the presence of PRC2 at the Sox 8 locus. PRC2 is the multi-protein complex responsible for catalysing the methylation of H3K27. A common feature of the mammalian PRC2-binding region is the presence of $\mathrm{CpG}$ islands (CGIs) and more specifically, CpG-rich regions which are adjacent to the TSS of silenced genes. Multiple studies indicate that high-density DNA methylation seems to be mutually exclusive with PRC2 since most of the CGIs or CG-rich regions occupied by PRC2 are hypomethylated (Yang and Li, 2020). In agreement with these studies, the levels of methylation are lower at the promoter of Sox8, which is situated within the $\mathrm{CpG}$ island, in the $\mathrm{Sox} 8$ transcriptionally repressed state than in the active state.

Another factor influencing PRC2 binding to target loci is its interaction with RNA molecules. It is now believed that lncRNA interaction, including those with PARTICLE and Meg3, could be one of the mechanisms by which PRC2 gains target specificity (Mondal et al, 2015, O'Leary et al, 2016). Different subunits of PRC2 recognise and bind to different secondary structures/ DNA sequences through which they get targeted specifically to genomic loci. For instance, unmethylated GCG trinucleotide motif showing an unwound DNA helix can specifically recruit PRC2-MTF2 while the Suz12 subunit has been reported to bind to the two-hairpin motif present in RNA molecules. PRC2 subunit JARID2 preferentially binds to GC rich DNA sequences (Yang and Li, 2020). At the Sox8 locus, multiple possible modes of recruitment of PRC2 exist, namely, the presence of a hypomethylated $\mathrm{CpG}$ island, the presence of $M r h l$ lncRNA and also the formation of triplex by $M r h l$ lncRNA. 
350

351

352

353

354

355

356

357

358

359

360

361

362

363

364

365

366

367

368

369

370

371

372

373

374

375

376

377

378

379

380

381

382

383

Through functional rescue with wild type and TFO mutant Mrhl, we have shown that triplex formation indeed recruits PRC2 to the Sox 8 locus.

\section{CTCF and cohesin in Sox8 gene regulation}

CTCF in mammals is the master architectural protein and along with cohesin, has been implicated in organizing chromatin architecture at different genomic scales from chromatin loops at the scale of a single locus to the organization of TADs. Using a combinatorial approach, we show the Mrhl dependent occupancy of CTCF and cohesin at the Sox8 locus along with the DEAD-box RNA helicase p68. The popular loop-extrusion model of chromatin loop formation proposes that the cohesin protein complex slides along chromatin forming a growing loop until it meets two CTCF molecules bound with convergent orientation. This prevents cohesin from sliding further. Preliminary in silico analysis suggests the presence of CTCF binding sites both at the promoter and within exon 3 of Sox 8 (supplementary table 1). A limitation of the prediction software utilised for this study is that it does not exhaustively predict the presence of all CTCF binding sites present within the sequence but only the sequence with the highest score. Heterogeneity is observed in CTCF binding motifs. In each species, the CTCF binding profile is composed of substantial numbers of both deeply conserved and evolutionarily recent sites. CTCF binding sites at TAD boundaries are highly conserved across species while evolutionarily recent sites play a role in modulating gene regulation (Kentepozidou et al, 2020). Further, cell-type specific CTCF bound sites have also been reported to have a varied binding motif as compared to constitutively bound sites (Essien et al, 2009). This is a likely explanation for why CTCF binding site was not predicted to be present by the GPMiner tool (Fig. 5A).

CTCFL is a testis-specific paralog that is expressed only transiently in pre-meiotic male germ cells together with CTCF and the two paralogs compete for binding at a subset of the CTCF binding sites (Nishana et al, 2020). CTCFL functions as a transcription factor and does not have a role in chromatin organisation since it can't anchor cohesin to chromatin like CTCF can (Pugacheva et al, 2020). ChIP qPCR using CTCF specific antibody in the spermatogonial cells performed by us (supplementary figure 7) further confirms that CTCF and not CTCFL is bound at the Sox 8 locus.

DNA methylation at the DMR regulating the imprinting at the H19/Igf2 locus prevents the binding of CTCF to its cognate binding site within the DMR. The slight increase in the methylation at the CpG island of the Sox 8 promoter (supplementary 1D) upon its transcriptional activation may possibly serve the same purpose.

\section{Silencer and enhancer elements in Sox8 gene regulation}

In addition to promoters, silencers/insulators and enhancers together make up cis-regulatory elements (CREs) of a gene. H3K27me3 mark enrichment has been found to be enriched within silencer elements. Most $\mathrm{H} 3 \mathrm{~K} 27 \mathrm{me}^{+}{ }^{+}$silencer elements are also DNase I Hypersensitive and have binding 
384

385

386

387

388

389

390

391

392

393

394

395

396

397

398

399

400

401

402

403

404

405

406

407

408

409

410

411

412

413

414

415

416

417

sites for ubiquitous repressors such as CTCF, SMAD group of proteins and tissue specific TFBS (Huang, D. et al, 2019). Additionally, many H3K27me3-DHS coincided with active histone modifications such as H3K4me1 and H3K27ac. The element within exon 3 has many of these characteristics. In addition to the occupancy of CTCF and cohesin within this genomic region, ENSEMBL database suggests that this element is DNase hypersensitive and shows the presence of both H3K4me1 and $\mathrm{K} 3 \mathrm{~K} 27 \mathrm{me}$. The results of the $3 \mathrm{C}$ experiment further indicate that this element contacts the gene promoter in the transcriptionally repressed state. Taken together, this evidence supports the 'silencer' function of exon 3 of Sox8.

We have identified two putative enhancers for Sox 8 in spermatogonial cells located downstream of the gene. We observe activity at both these enhancer elements upon Mrhl knockdown as evidenced from enhancer specific histone modification ChIP experiments. Only one of these two regions, the enhancer present $8 \mathrm{~kb}$ downstream, contacts the promoter of $50 x 8$ as observed from the $3 \mathrm{C}$ experiment and is likely to drive the expression of Sox 8 in meiotically committed spermatogonia. This enhancer harbours within it one of the evolutionarily conserved elements, E6 (Guth et al, 2010), as a putative enhancer. However, this does not mean that the other enhancer element has no role to play in regulating Sox8 expression or that the E6 harbouring enhancer is the sole enhancer regulating the expression of Sox8. Further, this study has been performed in embryonic gonads and gives us no information on the postnatal activity of this regulatory element. The possibility that E6 harbouring enhancer may not be a testis-specific enhancer exists.

Sox9 is regulated by multiple tissue specific enhancers and in the testis alone, is regulated by multiple enhancers acting either redundantly or synergistically (Gonen et al, 2018, Croft et al, 2018). Our study has focussed on characterising the regulatory elements of Sox8 in a genomic region of 25$30 \mathrm{~kb}$ only. Extensive characterisation including genomic deletion of the regulatory elements in a larger region is required to identify and better understand the possible interplay between various enhancers in regulating Sox 8 expression. Such characterisation is beyond the scope of the current study. Further, the possibility of trans- interactions regulating Sox8 expression has not been explored.

\section{YY1 in Sox8 gene regulation}

Of all the regulatory proteins identified at the Sox8 locus, YY1 is the only one with contradictory functional roles. YY1 can act both as a transcriptionally activator or transcriptional repressor in a context dependent manner. As an architectural protein too, YY1 can mediate the formation of chromatin loops which can either have gene repressive or activating outcomes.YY1 dimerises with CTCF to mediate chromatin loop formation to repress E6 and E7 oncogenes of the human papillomavirus genome in infected cells (Pentland et al, 2018). At the same time, YY1 binds to promoter- 
418 proximal elements and active enhancers and forms dimers that facilitate the interaction of these

419 DNA elements (Weintraub et al, 2017). Thus YY1 at the Sox8 locus was a wildcard that could be

420 involved in either function. However, the results from the ChIP experiments clearly indicated the 421 association of YY1 at the regulatory elements only in the Sox 8 transcriptionally active state. Fur-

422 ther, the occupancy of YY1 at the promoter and enhancer elements suggested a role for it in facili-

423 tating the interaction of the enhancer with the promoter and this has been validated by chromosome 424 conformation capture.

$425 M r h l$ lncRNA possible possesses multiple functional domains within it. At the Sox8 locus, a region 426 from the 5' end of the lncRNA participates in triplex formation. Results from previous work sug427 gest that a region towards the 3' end of Mrhl is involved in its interaction with p68 (unpublished 428 data). The gene regulatory function is an outcome of the combinatorial function of all the different 429 domains of Mrhl. Further, many lncRNAs involved in 3D genome organisation have been reported 430 to interact directly with CTCF. It remains to be seen whether Mrhl lncRNA also physically interacts 431 with CTCF directly. Mrhl, then, can be categorised as scaffold lncRNA which functions to bring together multiple regulatory proteins at the target locus.

433 In the current study, we have demonstrated that the lncRNA Mrhl is involved in mediating chroma434 tin looping at the Sox8 locus in association with the architectural proteins CTCF and cohesin to 435 maintain the gene in the transcriptionally repressed state. The downregulation of Mrhl lncRNA re436 sults in a rearrangement of the looping interaction at the locus whereby the promoter-silencer con437 tact gives way to a promoter-enhancer contact mediated by YY1. Further, Mrhl forms a 438 DNA:DNA:RNA triplex at the distal promoter of Sox 8 that is required for the recruitment of PRC2 439 which then tri-methylates H3K27 at Sox8 gene locus (summarised in fig. 7).

440 The mechanism of silencing at the Sox 8 locus by Mrhl lncRNA via triplex formation, PRC2 re441 cruitment, and the involvement of CTCF, cohesin and p68 fits into the growing theme of gene si442 lencing mechanism by lncRNAs. Stating that Mrhl associates with this protein complex to mediate 443 the formation of a repressive loop is a simplistic view of events. Taking into account the very large 444 size of the repressive complex made up of CTCF, cohesin complex, Sin3a, HDAC1, Mad-Max 445 transcription factor dimer, p68, PRC2 and Mrhl, it would be more realistic to state that Mrhl creates 446 a repressive environment around the Sox8 locus.

447 In the recent update of ENSEMBL, the human Sox8 locus can be seen to not only contain a con448 served CTCF binding site in exon 3 but also has binding of many of the regulatory protein observed 449 at the mouse Sox 8 locus. While the data is indicative of a conserved regulatory mechanism, the in450 volvement of a lncRNA in the regulation of Sox 8 in humans remains to be seen. 
451

452

453

454

455

456

457

458

459

460

461

462

463

464

465

466

467

468

469

470

471

472

473

474

475

476

477

478

479

480

481

482

In summary, we have delineated the detailed molecular mechanism of regulation of Sox 8 gene expression by Mrhl lncRNA which has significant implications towards our understanding the role of Sox 8 in male germ cell differentiation, particularly meiotic commitment of B-type spermatogonia.

\section{Materials and Methods:}

\section{Cell lines and reagents:}

Gc1-spg cell line (CRL-2053) was obtained from ATCC . L-control cell line (ATCC CRL-2648) and L-Wnt3A cell line (ATCC CRL-2647) were kind gifts from Dr. Jomon Joseph (NCCS, India).

All chemical reagents were purchased from Sigma-Aldrich and were of analytical reagent (AR) grade. Lipofectamine 2000 (11668027) and Protein A dynabeads (10002D) were purchased from Invitrogen. cDNA synthesis reagents were procured from Thermo Fisher Scientific. DpnII restriction enzyme (R0543), DNase I (MO303) and T4 DNA ligase (M0202S) were purchased from New England BioLabs. Mrhl shRNAs (custom synthesised) and non-target control (SHC332) were procured from Sigma-Aldrich. qPCR was performed using BioRad's CFX96 machine. DNeasy Blood and Tissue kit (69504), EpiTect II DNA Methylation Enzyme Kit (335452) and EpiTect methyl II PCR system (EPMM104707-1A) for CpG methylation analysis was procured from Qiagen. $[\gamma-32 \mathrm{P}] \mathrm{ATP}$ was sourced from

List of antibodies that were used are as follows with the manufacturer and catalog number in parenthesis are: CTCF (AbCam; ab188408), (Cell Signaling Technology; 3418), Rad21 (AbCam; ad9920), p68/DDX5 ( Cusabio; CSB-PA003685), YY1 (Diagenode; C15410345), H3K4me1 (Diagenode; C15410037), H3K27ac (Diagenode; C15410174), Ezh2 (Diagenode; C15410039).

\section{Cell Culture and preparation of Control and Wnt3A conditioned media:}

Gc1-spg cells were cultured in Dulbecco's modified Eagle's Media (DMEM) supplemented with $10 \%$ Fetal Bovine Serum (FBS) and Penicillin/Streptomycin.

Preparation of control and Wnt3A conditioned media was done as per manufacturer's (ATCC) instructions. The collected media was centrifuged at $500 \mathrm{Xg}$ for $5 \mathrm{~min}$ and used after filter sterilisation.

Gc1-spg cells were grown in control or Wnt conditioned media for 72 hours for Wnt induction.

All cell-lines were checked for Mycoplasma contamination every 2 months 
483

484

485

486

487

488

489

490

491

492

493

494

495

496

497

498

499

500

501

502

503

504

505

506

507

508

509

510

511

512

513

514

515

516

517

\section{Generation of stable knockdown lines}

All shRNA plasmids were transfected at a concentration of $1.5 \mu \mathrm{g} / \mathrm{ml}$ Lipofectamine 2000 at $70 \%$ cell confluence. To select for positive transfectants, cells were grown in selection media containing puromycin at a final concentration of $3 \mathrm{ug} / \mathrm{ml}$ for 72 hours. To induce shRNA expression, cells were grown in complete media in the presence of $0.5 \mathrm{mM}$ IPTG and $2.5 \mathrm{ug} / \mathrm{ml}$ puromycin for 96 hours.

\section{Cloning}

Full length WT mrhl and TFO mutant mrhl was cloned into pCDNA3.1 vector between the HindIII and BamHI sites. Clones were confirmed by Sanger sequencing.

\section{Preparation of the mice testicular samples:}

The testicular samples prepared were harvested from BALB/C mice in the ages groups of $7 \mathrm{dpp}$ and $21 \mathrm{dpp}$. The dissected testis was decapsulated in PBS (pH 7.4) on ice by removing the tunica albuginca. The seminiferous tubules were released into PBS (pH7.4) and subjected to homogenization to procure a single-cell suspension.

\section{Chromatin immunoprecipitation:}

ChIP was performed as previously described (Kataruka et al, 2017). Briefly, crosslinked cells were resuspended in SDS lysis buffer (1\% SDS, $10 \mathrm{mM}$ EDTA, $50 \mathrm{mM}$ Tris-HCl). This was followed by sonication of the lysate to enrich for chromatin in the size range of 200-600bp.After removal of debris by contrifugation, the lysate was incubated with either 3-5ug specific antibody or corresponding amount of isotype control for immunoprecipitation overnight. The immune complexes were allowed to bind to protein A Dynabeads and the beads bound by immune complexes were subjected to washes with low-salt buffer $(0.1 \%$ SDS, 1\% Triton X-100, 2 mM EDTA, 20 mM Tris-HCl, 150 $\mathrm{mM} \mathrm{NaCl})$, high-salt buffer (0.1\% SDS, 1\% Triton X-100, 2 mM EDTA, 20 mM Tris-HCl, 500 $\mathrm{mM} \mathrm{NaCl}), \mathrm{LiCl}$ wash buffer (1\%NP-40, 1\% Sodium deoxycholate, 1mM EDTA, 10mM Tris-Cl $\mathrm{pH}$ 8.0) and T.E (10mM Tris-Cl pH 8.0, 1mM EDTA). The beads were then either processed directly for western blotting or the immunoprecipitated material was eluted from the beads by adding elution buffer $(0.1 \mathrm{M} \mathrm{NaHCO}$, 1\% SDS). The supernatant treated with Proteinase $\mathrm{K}$ (Life Technologies) and crosslinks were reversed. Eluted DNA was used for real-time PCR.

\section{Western blotting:}

After SDS-PAGE and transfer, the membranes were blocked in 5\% skimmed milk for 1 hour at room temperature and then incubated with the respective primary antibody dissolved in $1 \%$ skimmed milk prepared in 1 XPBS with $0.1 \%$ Tween $20(0.1 \%$ PBST). The membrane was then 
washed with $0.1 \%$ PBST and incubated with the respective secondary antibody dissolved in $1 \%$ skimmed milk for an hour at room temperature. Washes were then given using $0.1 \%$ PBST, and the blot was developed using Millipore's Immobilion Forte Western HRP substrate and the image was captured on BioRad's ChemiDoc.

522

\section{Circular Dichroism spectroscopy}

524 CD-spectra were recorded on a Jasco 500A spectropolarimeter. Each spectrum is the average of 4 525 consecutive spectra (independent replicates) and baseline- corrected with a spectrum of pure buffer. 526 CD-spectra were recorded on $m r h l$ ssRNA TFO, NC ssRNA TFO and the dsDNA oligos separately 527 as well as on a 1:1 mix of the two in $1 \mathrm{X}$ triplex forming buffer $(10 \mathrm{mM}$ Tris $\mathrm{pH} 7.5,25 \mathrm{mM} \mathrm{NaCl}$ 528 and $10 \mathrm{mM} \mathrm{MgCl2}$ ). The mixed samples or individual RNA and dsDNAs were heated to $70^{\circ} \mathrm{C}$ for 52910 minutes and slowly cooled to room temperature and incubated at room temperature for 2 hours. 530 The samples were incubated overnight at $4{ }^{\circ} \mathrm{C}$. The measurements were performed at $5^{\circ} \mathrm{C}$ The data 531 presented in the spectra is the Molar Ellipticity given based on the concentration of nucleotides in 532 the samples.

\section{Triplex Electrophoretic Mobility Shift Assay}

535 Electrophoretic mobility shift assay was performed as per protocol of Mondal et al (Mondal et al, 536 2015). Double stranded Oligonucleotides were end-labeled with T4 polynucleotide kinase in the 537 presence of $[\gamma-32 \mathrm{P}] \mathrm{ATP}$ and purified using G-25 columns (GE Healthcare). To remove secondary 538 structures present in them, RNA oligonucleotides were heated at $70^{\circ} \mathrm{C}$ and incubated on ice. Binding reaction was carried out in using labeled dsDNA oligonucleotides (corresponding to 10,000cpm), 1X Triplex forming buffer and 50 times molar excess of RNA oligonucleotides and incubated for 6 hours at room temperature. In control assay, triplex reaction was treated with either

5425 units of RNase H (NEB) or $10 \mu \mathrm{g}$ of RNase A (Life Technologies) for 20min. Triplex formation 543 was monitored on $20 \%$ polyacrylamide TBE gel in 1X TBE buffer supplemented with $8 \mathrm{mM}$ $544 \mathrm{MgCl}$. The gel was dried and exposed to X-ray films.

\section{In vitro triplex pulldown assay}

547 Nuclei from Gc1-spg cells were prepared by resuspending the cells in 1X nuclei isolation buffer 548 (40mM Tris- $\mathrm{HCl} \mathrm{pH} 7.5,20 \mathrm{mM} \mathrm{MgCl2}$, 4\% tritonX-100, 1.28M sucrose). $10 \mu \mathrm{M}$ psoralen549 biotinylated TFO1 or NC TFO RNA oligonucleotides (purchased from Sigma-Aldrich) were incu550 bated with the Gc1-spg nuclei for 2.5 hours at $30^{\circ} \mathrm{C}$ in $1 \mathrm{X}$ Triplex forming buffer followed by 10 551 minutes of UV treatment to induce photo-adduct formation. Nuclei were lysed using Bioruptor (10 552 cycles, $30 \mathrm{sec}$ ON and 30sec OFF, Diagenode). The Supernatants were incubated with $50 \mu 1$ strep- 
553

554

555

556

557

558

559

560

561

562

563

564

565

566

567

568

569

570

571

572

573

574

575

576

577

578

579

580

581

582

583

584

585

tavidin-magnetic beads at $30^{\circ} \mathrm{C}$. In case of RNase $\mathrm{H}$ control reaction, the supernatants were treated with 15 units of RNase $\mathrm{H}$ for 20 min before streptavidin-magnetic beads were added. Following beads capture, the beads were washed in $1 \mathrm{X}$ Triplex forming buffer to remove the non-specifically bound DNA fragments and then beads were resuspended in DNA isolation buffer. Resuspended beads bound to DNA-RNA triplex were treated with RNase A $(20 \mu \mathrm{g})$ for 30 minutes followed by Proteinase K treatment. Precipitated DNA was used as template for qPCR.

\section{Chromosome conformation capture assay}

BAC plasmids containing the Sox8 locus (RP23-70O24) and the control Ercc3 locus (RP23148C24) (BACPAC resources, California) were purified by Alkaline Lysis method. The plasmids were mixed in equimolar ratio and $20 \mu \mathrm{g}$ of mixed plasmid was subjected to restriction digestion with the enzyme Sau3AI (NEB, Catalog number: R0169) (Isoschizomer of DpnII) overnight at $37^{\circ} \mathrm{C}$. DNA was precipitated and resuspended in ligation master mix (1X NEB Ligation buffer, $0.8 \%$ Triton X-100, 0.5X BSA, $1600 \mathrm{U}$ of T4 DNA ligase (NEB, Catalog number: M0202). The reaction was incubated at $21^{\circ} \mathrm{C}$ for 4 hours. Ligated DNA was precipitated and used as a template for PCR.

Contact library was generated as described by Mumbach et al (Mumbach et al, 2016) with modifications. Briefly, nuclei were isolated from crosslinked cells by resuspending cells in cell lysis buffer (10mM Tris-Cl pH 8.0, 1.5mM MgCl2, $10 \mathrm{mM} \mathrm{KCl,0.5mM} \mathrm{DTT,} 0.05 \% \mathrm{NP}-40,1 \mathrm{X} \mathrm{mPIC}$ and $0.2 \mu \mathrm{M}$ PMSF) and incubating on ice for 30 minutes. Pelleted nuclei were washed once with cell lysis buffer and permeabilised using $0.7 \%$ SDS by incubating at $62^{\circ} \mathrm{C}$ for 15 minutes. Triton $\mathrm{X}-100$ was added to a final concentration of $10 \%$. 50 1 l of $10 \mathrm{X}$ DpnII buffer and 375U of DpnII (NEB, Catalog number: R0543) restriction enzyme was added and the reaction was incubated overnight at $37^{\circ} \mathrm{C}$ with shaking at $900 \mathrm{rpm}$. The reaction was heat inactivated at $62^{\circ} \mathrm{C}$ for 20 minutes. In-situ ligation was carried out by adding ligation master mix and incubating at $21^{\circ} \mathrm{C}$ for 4 hours with shaking. Nuclei were pelleted and resuspended in SDS Lysis Buffer. The lysate was subjected to proteinase $\mathrm{K}$ treatment and reverse-crosslinking overnight at $65^{\circ} \mathrm{C}$. DNA precipitated was then used as template for PCR. The relative frequency of interaction was calculated as described by Naumova et. al, (Naumova, N. et al, 2012) from agarose gel images.

\section{CpG methylation assay}

The methylation status at the Sox 8 promoter was scored for using the EpiTect methyl II PCR kit from QiaGen according to manufacturer's instructions. 


\section{Triplexator prediction}

587 To identify all putative triplexes that can form between $m r h l$ lncRNA and Sox 8 promoter, analysis

588

589

590

591

592

593

594

595

596

597

598

599

600

601

602

603

604

605

606

607

608

609

610

611

612

613

614

615

616

617

618

619

620

621

622 was run with default parameters (Buske et al, 2012) to identify TFO-TTS pairs in single-strand and duplex sequences.

\section{ChIP-sequencing data analysis}

Raw FASTQ files were downloaded from the NCBI GEO repository, and were re-analysed to generate the aligned files for the visualisation of regions of interest. All aligned files were aligned to mouse genome (mm10) using Bowtie2 (Langmead and Salzberg, 2012) and then sorted, indexed, made free from PCR duplicates using Samtools ( $\mathrm{Li}$ et al, 2009). Aligned files were loaded in the IGV genome browser to visualise the enrichment of peaks at the regions of interest. Peak calling was done with the MACS2 pipeline (Feng et al, 2012).

\section{RNA-sequencing data analysis}

Raw FASTQ files were downloaded from the NCBI GEO repository, and were re-analysed with the TopHat (Kim et al, 2013) and Cufflinks (Trapnell, C. et al, 2010) pipeline. Aligned files were loaded on the IGV genome browser (Robinson et al, 2011) to visualise the gene expression enrichment.

\section{IACUC approval:}

Experiments were performed using mice testes. The institution (JNCASR) has obtained IACUC approval for research involving use of mice.

\section{FUNDING}

This work was supported by the Department of Biotechnology, India (BT/01/COE/07/09 and DBT/INF/22/SP27679/2018). M.R.S.R. acknowledges Department of Science and Technology for J. C. Bose and S.E.R.B. Distinguished fellowships and The Year of Science Chair professorship.

Competing Interests: Authors declare no competing interests

\section{References:}

1. Akhade, V. S., Arun, G., Donakonda, S., \& Rao, M. R. (2014). Genome wide chromatin occupancy of mrhl RNA and its role in gene regulation in mouse spermatogonial cells. RNA Biol, $11(10), 1262-1279$.

2. Akhade, V. S., Dighe, S. N., Kataruka, S., \& Rao, M. R. (2016). Mechanism of Wnt signaling induced down regulation of mrhl long non-coding RNA in mouse spermatogonial cells. Nucleic Acids Res, 44(1), 387-401. 
623

624

625

626

627

628

629

630

631

632

633

634

635

636

637

638

639

640

641

642

643

644

645

646

647

648

649

650

651

652

653

654

655

656

657

658

659

660

661

662

663

664

665

666

667

668

669

670

671

672

673

3. Barrionuevo, F., \& Scherer, G. (2010). SOX E genes: SOX9 and SOX8 in mammalian testis development. Int J Biochem Cell Biol, 42(3), 433-436.

4. Barrionuevo, F. J., Hurtado, A., Kim, G. J., Real, F. M., Bakkali, M., Kopp, J. L., et al. (2016). Sox 9 and Sox 8 protect the adult testis from male-to-female genetic reprogramming and complete degeneration. Elife, 5 .

5. Blank-Giwojna, A., Postepska-Igielska, A., \& Grummt, I. (2019). lncRNA KHPS1 Activates a Poised Enhancer by Triplex-Dependent Recruitment of Epigenomic Regulators. Cell Rep, 26(11), 2904-2915.e2904.

6. Buske, F. A., Bauer, D. C., Mattick, J. S., \& Bailey, T. L. (2012). Triplexator: detecting nucleic acid triple helices in genomic and transcriptomic data. Genome Res, 22(7), 1372-1381.

7. Essien, K., Vigneau, S., Apreleva, S., Singh, L. N., Bartolomei, M. S., \& Hannenhalli, S. (2009). CTCF binding site classes exhibit distinct evolutionary, genomic, epigenomic and transcriptomic features. Genome Biol, 10(11), R131.

8. Feng, J., Liu, T., Qin, B., Zhang, Y., \& Liu, X. S. (2012). Identifying ChIP-seq enrichment using MACS. Nat Protoc, 7(9), 1728-1740.

9. Garcia-Moreno, S. A., Futtner, C. R., Salamone, I. M., Gonen, N., Lovell-Badge, R., \& Maatouk, D. M. (2019). Gonadal supporting cells acquire sex-specific chromatin landscapes during mammalian sex determination. Dev Biol, 446(2), 168-179.

10. Gonen, N., Futtner, C. R., Wood, S., Garcia-Moreno, S. A., Salamone, I. M., Samson, S. C., et al. (2018). Sex reversal following deletion of a single distal enhancer of. Science, 360(6396), 1469-1473.

11. Grote, P., \& Herrmann, B. G. (2013). The long non-coding RNA Fendrr links epigenetic control mechanisms to gene regulatory networks in mammalian embryogenesis. RNA Biol, 10(10), $1579-1585$.

12. Guth, S. I., Bösl, M. R., Sock, E., \& Wegner, M. (2010). Evolutionary conserved sequence elements with embryonic enhancer activity in the vicinity of the mammalian Sox 8 gene. Int $J$ Biochem Cell Biol, 42(3), 465-471.

13. Huang, D., Petrykowska, H. M., Miller, B. F., Elnitski, L., \& Ovcharenko, I. (2019). Identification of human silencers by correlating cross-tissue epigenetic profiles and gene expression. Genome Res, 29(4), 657-667.

14. Kalwa, M., Hänzelmann, S., Otto, S., Kuo, C. C., Franzen, J., Joussen, S., et al. (2016). The lncRNA HOTAIR impacts on mesenchymal stem cells via triple helix formation. Nucleic Acids Res, 44(22), 10631-10643.

15. Kataruka, S., Akhade, V. S., Kayyar, B., \& Rao, M. R. S. (2017). Mrhl Long Noncoding RNA Mediates Meiotic Commitment of Mouse Spermatogonial Cells by Regulating Sox8 Expression. Mol Cell Biol, 37(14). 
674

675

676

677

678

679

680

681

682

683

684

685

686

687

688

689

690

691

692

693

694

695

696

697

698

699

700

701

702

703

704

705

706

707

708

709

710

711

712

713

714

715

716

717

718

719

720

721

722

723

724

16. Kentepozidou, E., Aitken, S. J., Feig, C., Stefflova, K., Ibarra-Soria, X., Odom, D. T., et al. (2020). Clustered CTCF binding is an evolutionary mechanism to maintain topologically associating domains. Genome Biol, 2l(1), 5.

17. Kim, D., Pertea, G., Trapnell, C., Pimentel, H., Kelley, R., \& Salzberg, S. L. (2013). TopHat2: accurate alignment of transcriptomes in the presence of insertions, deletions and gene fusions. Genome Biol, 14(4), R36.

18. Langmead, B., \& Salzberg, S. L. (2012). Fast gapped-read alignment with Bowtie 2. Nat Methods, 9(4), 357-359.

19. Li, H., Handsaker, B., Wysoker, A., Fennell, T., Ruan, J., Homer, N., et al. (2009). The Sequence Alignment/Map format and SAMtools. Bioinformatics, 25(16), 2078-2079.

20. Mondal, T., Subhash, S., Vaid, R., Enroth, S., Uday, S., Reinius, B., et al. (2015). MEG3 long noncoding RNA regulates the TGF- $\beta$ pathway genes through formation of RNA-DNA triplex structures. Nat Commun, 6, 7743.

21. Mumbach, M. R., Rubin, A. J., Flynn, R. A., Dai, C., Khavari, P. A., Greenleaf, W. J., et al. (2016). HiChIP: efficient and sensitive analysis of protein-directed genome architecture. Nat Methods, 13(11), 919-922.

22. Naumova, N., Smith, E. M., Zhan, Y., \& Dekker, J. (2012). Analysis of long-range chromatin interactions using Chromosome Conformation Capture. Methods, 58(3), 192-203.

23. Nishant, K. T., Ravishankar, H., \& Rao, M. R. (2004). Characterization of a mouse recombination hot spot locus encoding a novel non-protein-coding RNA. Mol Cell Biol, 24(12), 56205634 .

24. O'Bryan, M. K., Takada, S., Kennedy, C. L., Scott, G., Harada, S., Ray, M. K., et al. (2008). Sox8 is a critical regulator of adult Sertoli cell function and male fertility. Dev Biol, 316(2), 359-370.

25. O'Leary, V. B., Ovsepian, S. V., Carrascosa, L. G., Buske, F. A., Radulovic, V., Niyazi, M., et al. (2015). PARTICLE, a Triplex-Forming Long ncRNA, Regulates Locus-Specific Methylation in Response to Low-Dose Irradiation. Cell Rep, 11(3), 474-485.

26. Ogbourne, S., \& Antalis, T. M. (1998). Transcriptional control and the role of silencers in transcriptional regulation in eukaryotes. Biochem J, 331 ( Pt 1), 1-14.

27. Ong, C. T., \& Corces, V. G. (2014). CTCF: an architectural protein bridging genome topology and function. Nat Rev Genet, 15(4), 234-246.

28. Pal, D., Neha, C. V., Bhaduri, U., Zenia, Z., Dutta, S., Chidambaram, S., et al. (2021). LncRNA Mrhl orchestrates differentiation programs in mouse embryonic stem cells through chromatin mediated regulation. Stem Cell Res, 53, 102250.

29. Pentland, I., Campos-León, K., Cotic, M., Davies, K. J., Wood, C. D., Groves, I. J., et al. (2018). Disruption of CTCF-YY1-dependent looping of the human papillomavirus genome activates differentiation-induced viral oncogene transcription. PLoS Biol, 16(10), e2005752. 
30. Postepska-Igielska, A., Giwojna, A., Gasri-Plotnitsky, L., Schmitt, N., Dold, A., Ginsberg, D., et al. (2015). LncRNA Khps1 Regulates Expression of the Proto-oncogene SPHK1 via TriplexMediated Changes in Chromatin Structure. Mol Cell, 60(4), 626-636.

31. Richardson, N., Gillot, I., Gregoire, E. P., Youssef, S. A., de Rooij, D., de Bruin, A., et al. (2020). and. Elife, 9.

32. Robinson, J. T., Thorvaldsdóttir, H., Winckler, W., Guttman, M., Lander, E. S., Getz, G., et al. (2011). Integrative genomics viewer. Nat Biotechnol, 29(1), 24-26.

33. Saldaña-Meyer, R., González-Buendía, E., Guerrero, G., Narendra, V., Bonasio, R., RecillasTarga, F., et al. (2014). CTCF regulates the human p53 gene through direct interaction with its natural antisense transcript, Wrap53. Genes Dev, 28(7), 723-734.

34. Saldaña-Meyer, R., Rodriguez-Hernaez, J., Escobar, T., Nishana, M., Jácome-López, K., Nora, E. P., et al. (2019). RNA Interactions Are Essential for CTCF-Mediated Genome Organization. Mol Cell, 76(3), 412-422.e415.

35. Schmitz, K. M., Mayer, C., Postepska, A., \& Grummt, I. (2010). Interaction of noncoding RNA with the rDNA promoter mediates recruitment of DNMT3b and silencing of rRNA genes. Genes Dev, 24(20), 2264-2269.

36. Singh, A. P., Harada, S., \& Mishina, Y. (2009). Downstream genes of Sox 8 that would affect adult male fertility. Sex Dev, 3(1), 16-25.

37. Trapnell, C., Williams, B. A., Pertea, G., Mortazavi, A., Kwan, G., van Baren, M. J., et al. (2010). Transcript assembly and quantification by RNA-Seq reveals unannotated transcripts and isoform switching during cell differentiation. Nat Biotechnol, 28(5), 511-515.

38. Weintraub, A. S., Li, C. H., Zamudio, A. V., Sigova, A. A., Hannett, N. M., Day, D. S., et al. (2017). YY1 Is a Structural Regulator of Enhancer-Promoter Loops. Cell, 171(7), 15731588.e1528.

39. Xiang, J. F., Yin, Q. F., Chen, T., Zhang, Y., Zhang, X. O., Wu, Z., et al. (2014). Human colorectal cancer-specific CCAT1-L IncRNA regulates long-range chromatin interactions at the MYC locus. Cell Res, 24(5), 513-531.

40. Yang, Y., \& Li, G. (2020). Post-translational modifications of PRC2: signals directing its activity. Epigenetics Chromatin, 13(1), 47.

41. Yao, H., Brick, K., Evrard, Y., Xiao, T., Camerini-Otero, R. D., \& Felsenfeld, G. (2010). Mediation of CTCF transcriptional insulation by DEAD-box RNA-binding protein p68 and steroid receptor RNA activator SRA. Genes Dev, 24(22), 2543-2555.

42. Yao H, Brick K, Evrard Y, Xiao T, Camerini-Otero RD, Felsenfeld G. 2010. Mediation of CTCF transcriptional insulation by DEAD-box RNA-binding protein p68 and steroid receptor RNA activator SRA. Genes Dev 24:2543-2555. 


\begin{tabular}{|c|c|c|c|c|}
\hline $\begin{array}{c}\text { TFO start } \\
\text { (nucleotide } \\
\text { position within } \\
\text { mrhl) }\end{array}$ & $\begin{array}{c}\text { TFO end } \\
\text { (nucleotide } \\
\text { position within } \\
\text { mrhl) }\end{array}$ & $\begin{array}{c}\text { TTS start } \\
\text { (nucleotide } \\
\text { position from } \\
\text { TSS) }\end{array}$ & $\begin{array}{c}\text { TTS end } \\
\text { (nucleotide } \\
\text { position from } \\
\text { TSS) }\end{array}$ & Score \\
\hline 391 & 404 & 1224 & 1237 & 11 \\
\hline 389 & 400 & 1224 & 1235 & 10 \\
\hline 389 & 404 & 1226 & 1241 & 12 \\
\hline 389 & 404 & 1232 & 1247 & 12 \\
\hline 389 & 401 & 1245 & 1257 & 10 \\
\hline 2362 & 2374 & 1106 & 1118 & 10 \\
\hline 2362 & 2374 & 1239 & 1251 & 10 \\
\hline
\end{tabular}

Table 1- Triplexator predictions: predictions with a score of 10 and above for regions within mrhl lncrna (tfo start and end) and sox8 promoter (tts start and end)

\begin{tabular}{|l|l|c|c|c|c|}
\hline Motif PWM & Motif Sequence & $\begin{array}{c}\text { Input Se- } \\
\text { quence Name }\end{array}$ & $\begin{array}{c}\text { Motif } \\
\text { Length }\end{array}$ & $\begin{array}{c}\text { Motif Orien- } \\
\text { tation }\end{array}$ & Score \\
\hline EMBL_M1 & CGCCGCCTAGTGGA & exon3 & 14 & - & 12.427 \\
\hline EMBL_M1 & GGTCACCTGGTGGC & promoter & 14 & - & 10.1556 \\
\hline EMBL_M2 & GGAACAGCA & exon3 & 9 & + & 11.4118 \\
\hline EMBL_M2 & GTCACTGCC & promoter & 9 & - & 6.0656 \\
\hline MIT_LM2 & TGTCCACTAGGCGGCGCCC & exon3 & 19 & + & 7.22188 \\
\hline MIT_LM2 & GAGCCACCAGGTGACCCTG & promoter & 19 & + & 5.51758 \\
\hline MIT_LM7 & TGTCCACTAGGCGGCGCCCT & exon3 & 20 & + & 11.2928 \\
\hline MIT_LM7 & GAGCCACCAGGTGACCCTGG & promoter & 20 & + & 9.84716 \\
\hline
\end{tabular}

Supplementary Table 1 : Predicted CTCF binding site from CTCFBSDB 2.0 database based in the DNA sequences of Sox8 promoter and exon 3. All results with a score higher than 3 have been listed in the

\begin{tabular}{|l|c|}
\hline ChIP-seq datasets & GEO Accession number \\
\hline mESC CTCF & GSM723015 \\
\hline mESC SMC1 & GSM560341 \\
\hline mESC RNA Pol II & GSM723019 \\
\hline mESC H3K4me3 & GSM723017 \\
\hline mESC Input & GSM723020 \\
\hline Mouse brain cortex CTCF & GSM722631 \\
\hline Mouse brain cortex SMC1 & GSM1838869 \\
\hline Mouse brain cortex RNA PoIII & GSM722634 \\
\hline Mouse brain cortex H3K4me3 & GSM722633 \\
\hline Mouse brain cortex input & GSM722635 \\
\hline RNA-seq datasets & \\
\hline mESC & GSM723776 \\
\hline Adult Brain cortex & GSE96684 \\
\hline
\end{tabular}




\begin{tabular}{|c|c|c|}
\hline & Forward (5' - 3') & Reverse (5' - 3') \\
\hline \multicolumn{3}{|l|}{ Primers for $3 \mathrm{C}$} \\
\hline Sox C & CCAAGTGCAGCTAGGAGTCTCTC & \\
\hline Sox test 1 & AGCACCTGCGACACGGCATC & \\
\hline Sox test 2 & CTGGGAGCAGTACCTGCCAGAGG & \\
\hline Sox test 3 & GGCAGAAGTTTGGATATCCAGAAGC & \\
\hline Sox test 4 & GCCTGCCTCTGTCTACGCTTGG & \\
\hline Sox test 5 & CCAGTGCTTGAAACTCAATGGATGG & \\
\hline Sox test 6 & TCTCTCTGCTCGCCCTCATCC & \\
\hline Sox test 7 & CTGCAATCCCAGCACTGGAG & \\
\hline Ercc3 1 & CTGACCCTCAGCCTGTTAGAGC & \\
\hline Ercc3 2 & ACCAGTCTTGCCTTGTGTCAGC & \\
\hline \multicolumn{3}{|l|}{ ChIP RT primers } \\
\hline Sox8 promoter & AGAGGGCTAAGGGTGACTGACT & GTTTGGTTGCAATAGCGGATTC \\
\hline Sox8 exon3 & GATAACCTCGCTGCTGAGCTCGG & CTGGTGTCACCCACCAGCTCC \\
\hline Sox8 enhancer $8 \mathrm{~kb}$ & CCGCTATCCAGATCACCAGG & CTGCTGAGTGACCGATGAGAC \\
\hline Sox8 enhancer $16 \mathrm{~kb}$ & GCCTCAGGACTCACATCTGGC & TGTGGGTCCTTGCCAGGAGC \\
\hline Sox8 triplex region & $\begin{array}{l}\text { CCTTAATGGTGACCTTATTC- } \\
\text { TATTCTAG }\end{array}$ & CCTTTCTTGGCAGGTAATGG \\
\hline Actin promoter N.C. & CGCTCACTCACCGGCCTC & GTCCGGGCCTCGATGCTG \\
\hline Gene desert N.C. & TGGCTGTCCTGGCCTGC & GGCAGCCTATGCAGCATTCAATG \\
\hline \multicolumn{3}{|l|}{$\begin{array}{l}\text { Quantification } \\
\text { primers }\end{array}$} \\
\hline Mrhl & TGAGGACCATGGCTGGACTCT & AGATGCAGTTTCCAATGTCCAAAT \\
\hline Beta-actin & AGGTCATCACTATTGGCAACG & TACTCCTGCTTGCTGATCCAC \\
\hline Phkb & AAGCCCAGCAATGAGGACTC & AGCACCCACCACACTAACAC \\
\hline Sox8 & TGCTGAGCTCTGCGTTATGGAG & GTCTGGTGCCTATGCCTGTGC \\
\hline \multicolumn{3}{|l|}{ Cloning primers } \\
\hline Mrhl FP & ATGCAAGCTTTGACTTGCTCTTCATTAGATC & \\
\hline Mrhl TFO mut FP & $\begin{array}{l}\text { CATTGAAACTCACACACACACATGG- } \\
\text { CATCTCTCAGGTCAC }\end{array}$ & \\
\hline Mrhl TFO mut RP & $\begin{array}{l}\text { TGTGACCTGAGA- } \\
\text { GATGCCATGTGTGTGTGTGAGTTTCAATG }\end{array}$ & \\
\hline Mrhl RP & $\begin{array}{l}\text { ATGCGGATCCAGGAG- } \\
\text { GAATGAAGTATCCAC }\end{array}$ & \\
\hline \multicolumn{3}{|l|}{$\begin{array}{l}\text { EMSA oligonu- } \\
\text { cleotides }\end{array}$} \\
\hline $\begin{array}{l}\text { Positive control } \\
\text { DNA }\end{array}$ & AGAGAGAGGGAGAGAG & СТСТСТСССТСТСТСТ \\
\hline TTS1 & GGGAGGGAGACAGAGAGG & ССТСТСТGTСТСССТССС \\
\hline TTS2 & GGAAGAGGGAGGGAGA & ТСТСССТСССТТСТTСС \\
\hline TTS3 & AGACAGAGAGGGA & TCCCTCTCTGTCT \\
\hline TTS4 & AGCAGGAAGCAGG & CCTGCTTCCTGCT \\
\hline TTS5 & AGAGGGAAGAGGG & СССТСТТСССТСТ \\
\hline $\begin{array}{l}\text { TTS Negative con- } \\
\text { trol }\end{array}$ & ACCACGTGGGCCAGGCGC & GCGCCTGGCCCACGTGGT \\
\hline TTS mutant & GGAACACCCACCCAGA & TCTGGGTGGGTGTTCC \\
\hline
\end{tabular}


bioRxiv preprint doi: https://doi.org/10.1101/2021.10.05.463295; this version posted October 6, 2021. The copyright holder for this preprint (which was not certified by peer review) is the author/funder, who has granted bioRxiv a license to display the preprint in perpetuity. It is made available under aCC-BY-NC 4.0 International license.

778

779

780

781

\begin{tabular}{|l|l|l|}
\hline & & \\
\hline $\begin{array}{l}\text { Positive control } \\
\text { RNA }\end{array}$ & CGGAGAGCAGAGAGGGAGCG & \\
\hline TFO1 & UGAGAGAGAGAGAUGG & \\
\hline TFO2 & AGAAGAAGGAAGAC & \\
\hline $\begin{array}{l}\text { Negative control } \\
\text { RNA }\end{array}$ & CUUAUACUGCAUAAAU & \\
\hline $\begin{array}{l}\text { In nucleus pulldown } \\
\text { oligo }\end{array}$ & & \\
\hline TFO1 & $\begin{array}{l}\text { psoralen - UGAGAGAGAGAGAUGG - } \\
\text { biotin }\end{array}$ & \\
\hline NC TFO & psoralen - CUUAUACUGCAUAAAU- biotin & \\
\hline
\end{tabular}

Supplementary Table 3: List of all primers and oligonucleotides used for the current study

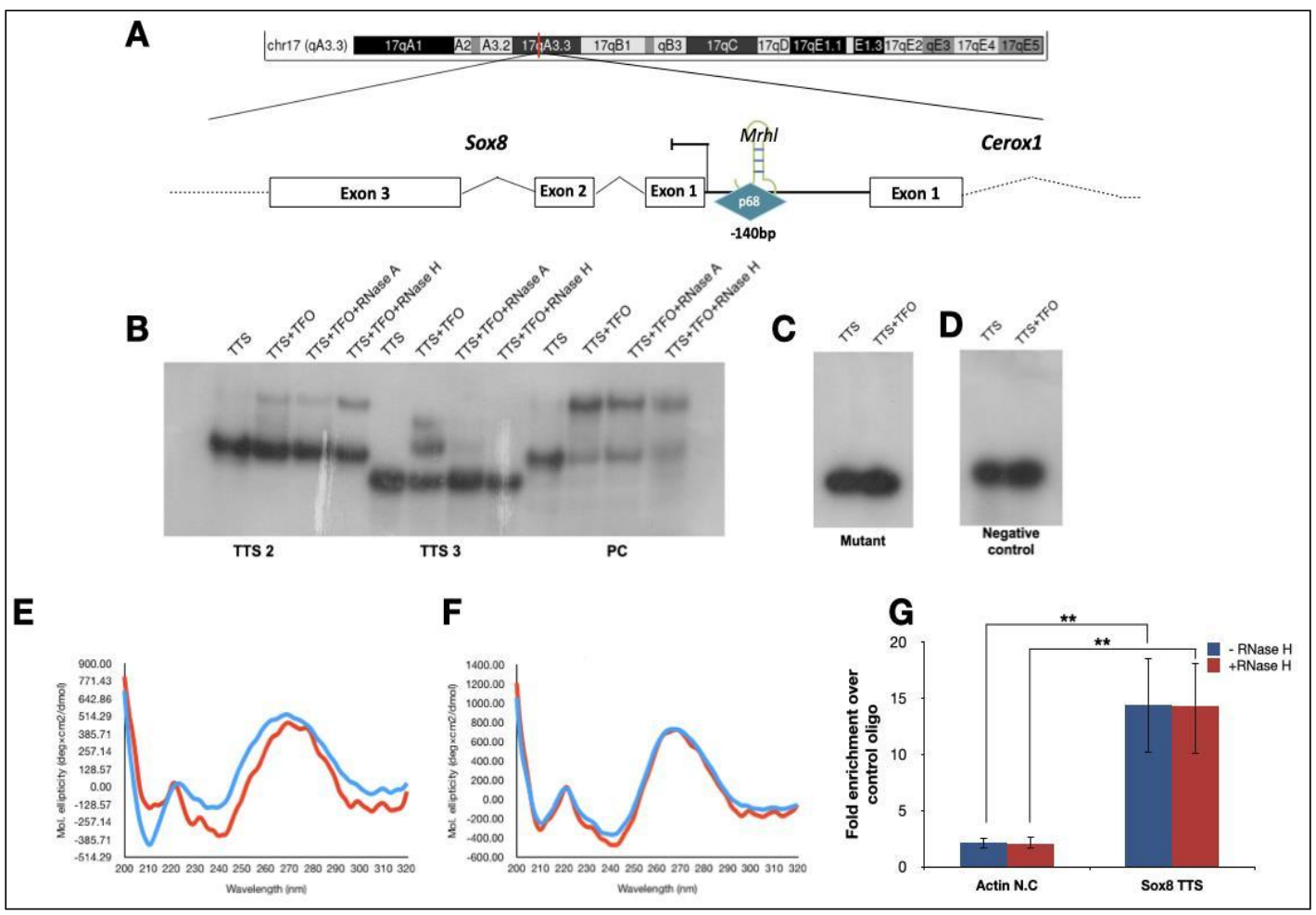

Fig 1: Mrhl interacts at the Sox8 locus. (A) The mouse Sox8 locus on chromosome 17 where Mrhl IncRNA binds at the bidirectional promoter 140bp upstream of the TSS in a p68-dependent manner to maintain Sox8 in the transcriptionally repressed state. (B) EMSA performed for the indicated DNA oligo incubated with RNA oligo TFO1. The lanes have the reaction components as indicated above them (C) EMSA performed with mutant TTS2 and RNA TFO1 where no shift in mobility is observed (D) EMSA for negative control TFO/TTS pair (E) Artificial spectrum generated by summation of individual CD spectra recorded for TTS2 only and NC TFO only (red) overlaid with CD spectrum of triplex reaction for the oligonucleotides, (F) Artificial spectrum generated by summation of individual CD spectra recorded for TTS2 only and TFO1 only (red) overlaid with CD spectrum of triplex reaction for the same oligonucleotides. Plots are an average of 4 independently recorded spectra. (G) Results of the in-nucleus triplex pulldown assay show significant enrichment of the Sox8 TTS region in the TFO1 oligo associated chromatin fraction over NC TFO associated chromatin fraction both without and with RNaseH digestion. Data in the graph has been plotted as mean \pm S.D. , $N=3$. ${ }^{* * *} P \leq 0.0005$, ${ }^{* *} P \leq 0.005, * P \leq 0.05$, N.S Not significant (two-tailed Student's $t$ test) 


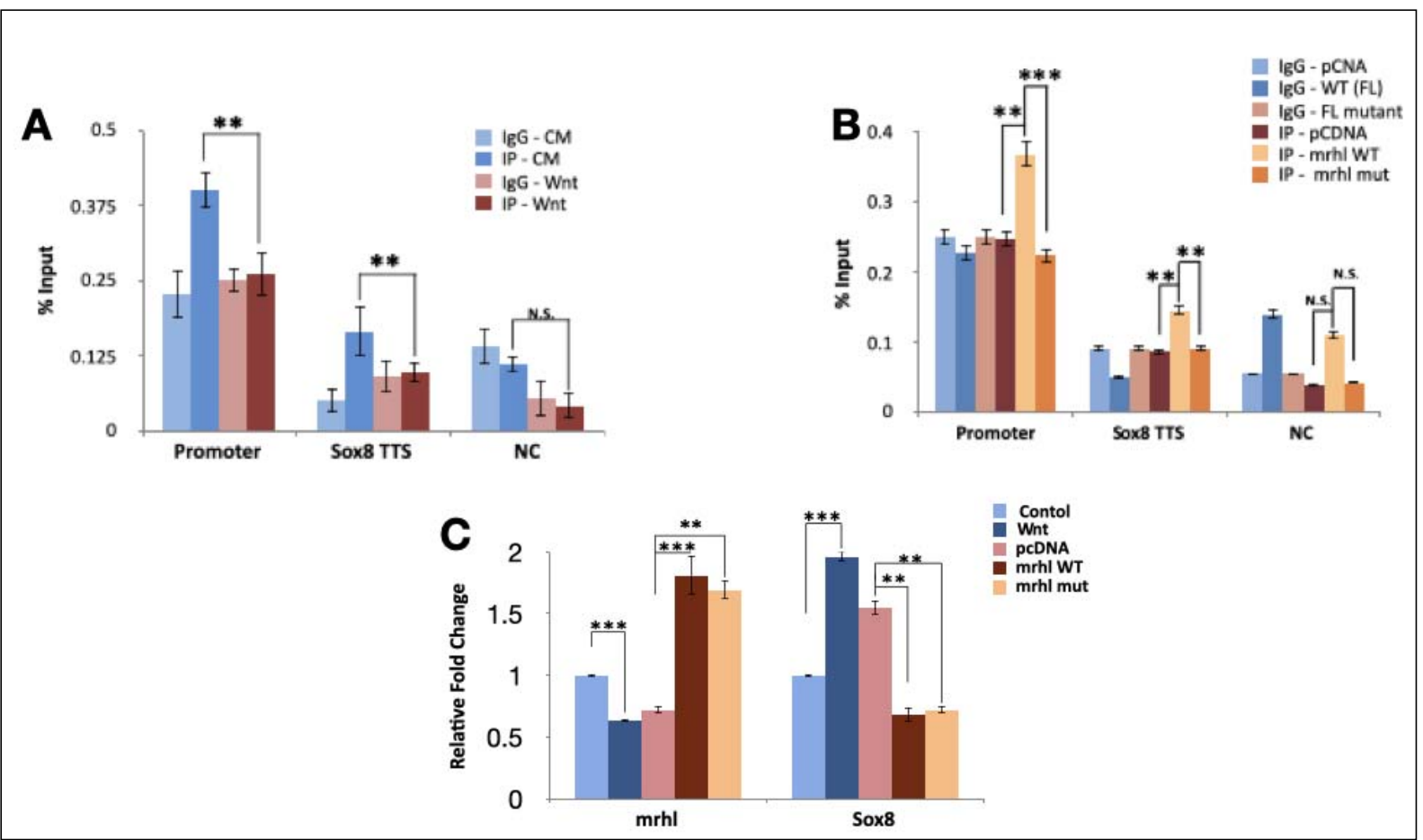

Fig 2: PRC2 occupancy at the Sox8 locus. (A) ChIP-qPCR for Ezh2 subunit of PRC2 at the Sox8 locus in Gc1-spg cells under control and Wnt signalling activated conditions. (B) ChIP-qPCR for Ezh2 performed in cells transfected with either vector control, WT or TFO mutant constructs of Mrhl. (C) The expression levels of Mrhl and Sox8 in cells grown under control or Wnt activated conditions and cells transfected with vector only control Mrhl WT and Mrhl TFO mutant constructs with Wnt activation. Data in the graph has been plotted as mean \pm S.D. , $N=3$. ${ }^{* * *} P \leq 0.0005,{ }^{* *} P \leq 0.005, * P \leq 0.05$, N.S - Not significant (twotailed Student's $t$ test)

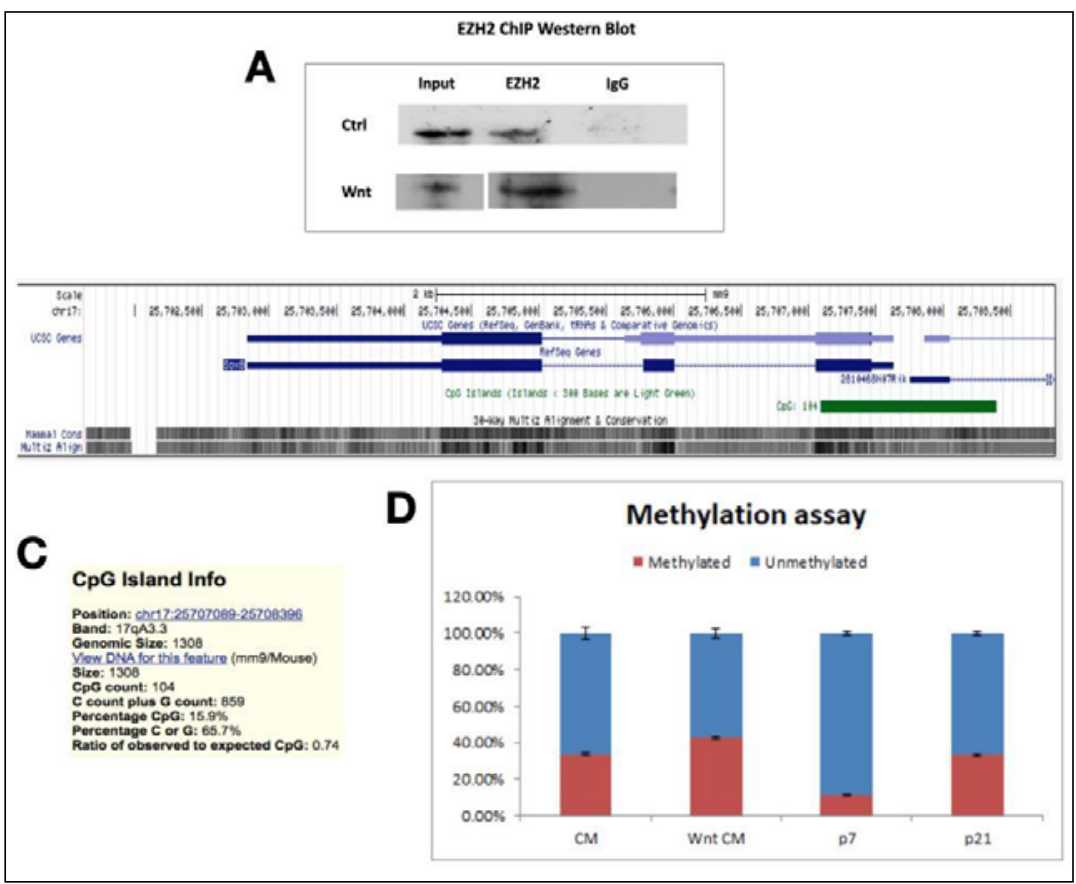

Fig. 2 supplementary: (A) ChIP wb for ezh2 performed in gc1-spg cells grown either in control or wnt media (B) $C p G$ island encompassing the sox8 promoter $(\boldsymbol{C})$ information about the $C p G$ island (D) \% CpG methylation at the sox $8 \mathrm{cpg}$ island in both cells (increase in wnt when compare to control) and mice testis (increase in p21 when compared to $p 7)$. Data in the graph has been plotted as mean \pm s.d. , $n=3$. 


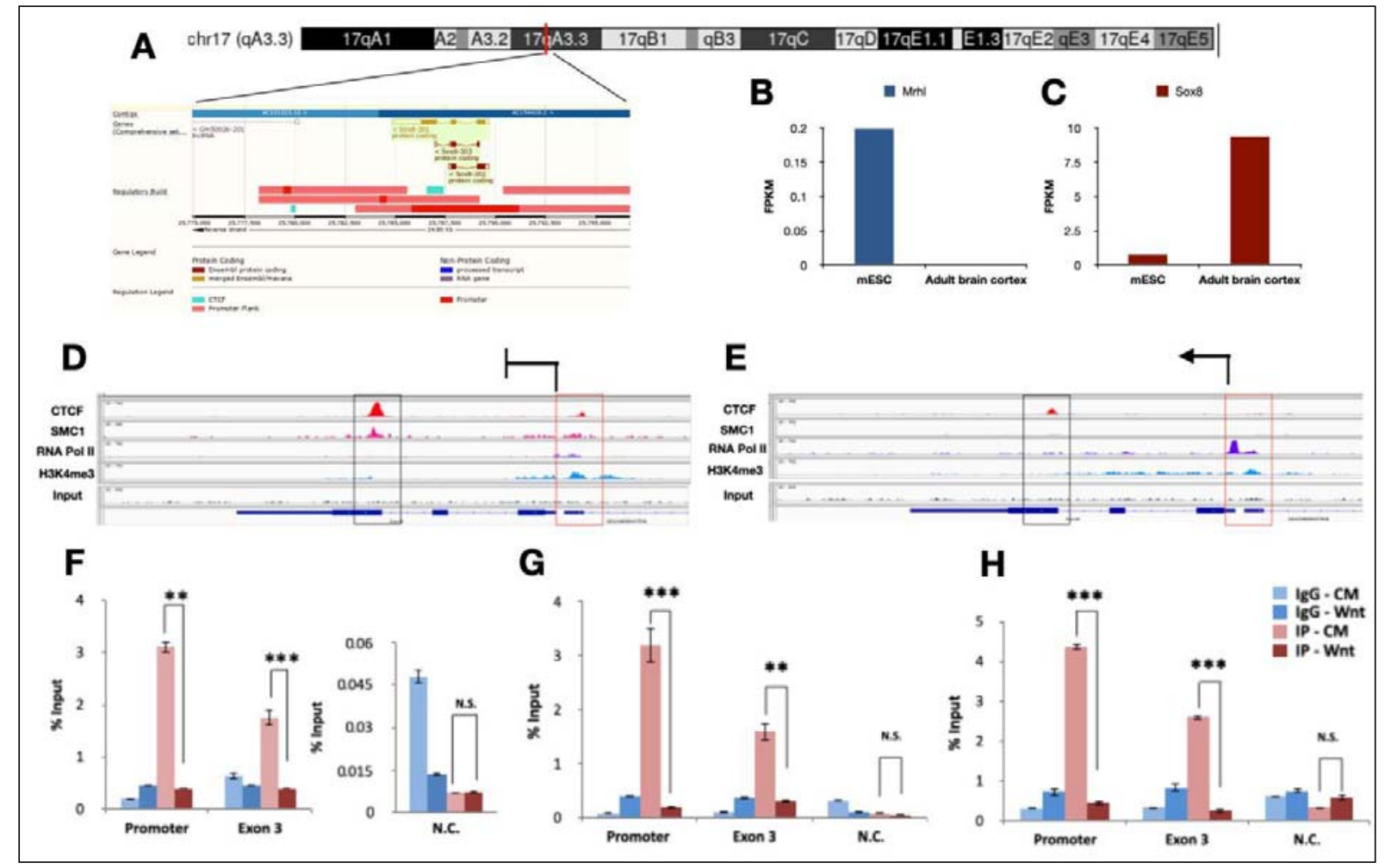

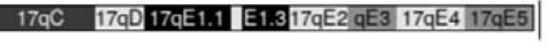

Fig 3: Occupancy of architectural proteins at the Sox8 locus in spermatogonia (A) Sox8 locus harbouring CTCF binding site within exon 3. (B) Mrhl expression levels in $m E S C$ and adult brain cortex $(\boldsymbol{C})$ Sox 8 expression in $m E S C$ and adult brain cortex (D) Analysis of ChIP-seq datasets in mESC showing the presence of CTCF and cohesin (SMC1) at both exon 3 and the promoter (E) Analysis of ChIP-seq datasets in adult brain cortex showing reduced occupancy of CTCF and cohesin (SMC1) at exon 3 and promoter. Results for ChIP-qPCR for $(\boldsymbol{F}) C T C F,(\boldsymbol{G})$ Rad21 and $(\boldsymbol{H})$ p68 showing their occupancy patterns at the promoter and exon3 of Sox 8 gene in cells without and with Wnt activation. Data in the graph has been plotted as mean \pm S.D. , N=3. ${ }^{* * *} P \leq 0.0005,{ }^{* *} P \leq 0.005, * P \leq 0.05$, N.S - Not significant (two-tailed Student's $t$ test) 


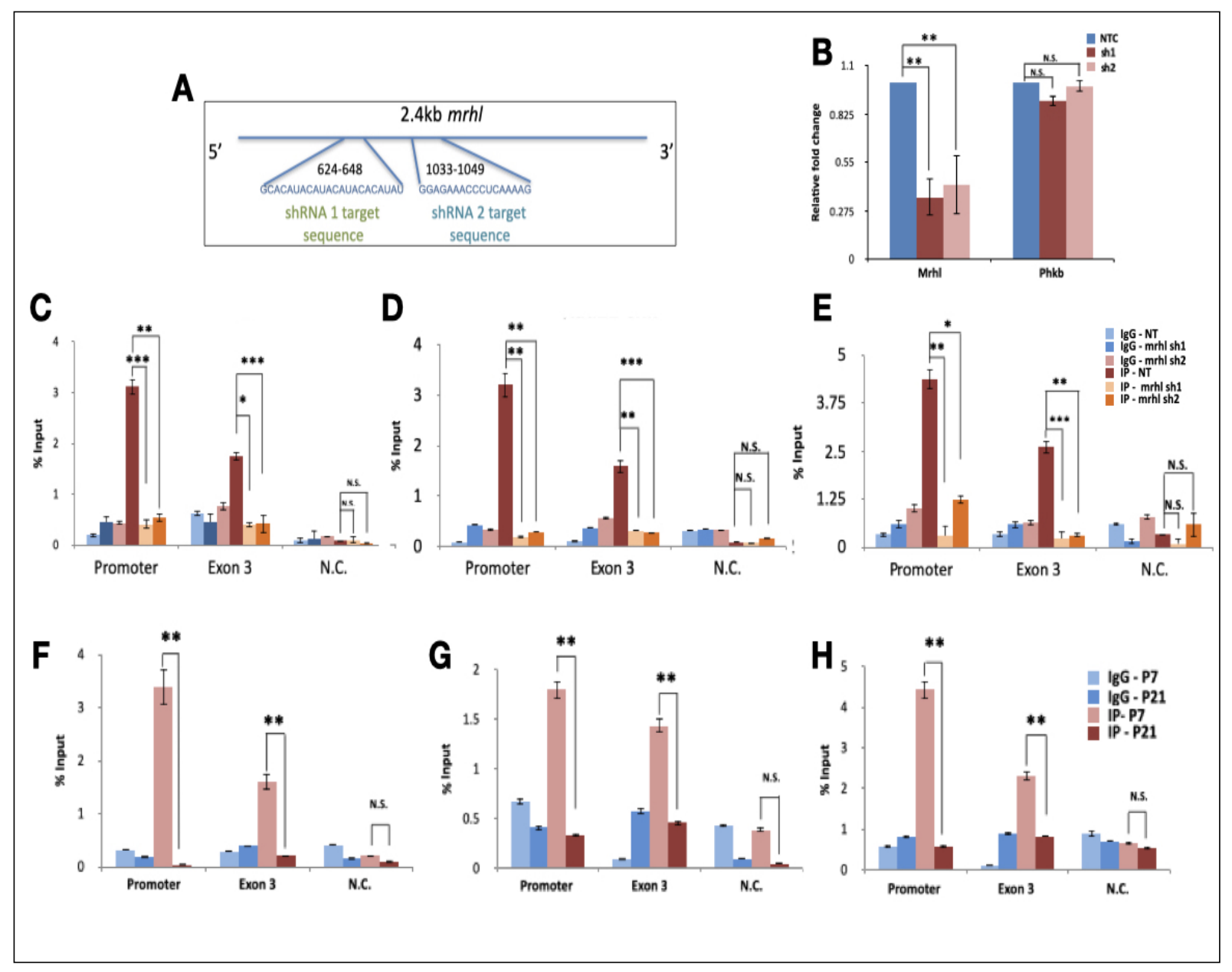

Fig 4: Architectural proteins at the Sox8 locus in Mrhl silenced cells and mice testes (A) The two different regions within Mrhl targeted by the two shRNA (B) Mrhl silencing efficiency of the two shRNAsilencing efficiencies of $\sim 65 \%$ and $\sim 55 \%$ respectively were observed for Mrhl while the transcript levels of the host phkb gene were not perturbed significantly. Results for ChIP-qPCR for (C)CTCF, (D) Rad21 of cohesin and (E) p68 show significant reduction in occupancy of CTCF at both the promoter and exon 3 of Sox8 upon induction of silencing of Mrhl with both shRNA construct 1 and shRNA construct 2. Occupancy of $(\boldsymbol{F})$ CTCF $(\boldsymbol{G})$ Rad21 and $(\boldsymbol{H})$ p68 is observed at the promoter and exon 3 of Sox 8 locus in P7 mice testes and a significantly reduced occupancy is observed in P21 mice testes. Data in the graph has been plotted as mean \pm S.D. , $N=3 .{ }^{* * *} P \leq 0.0005,{ }^{* *} P \leq 0.005,{ }^{*} P \leq 0.05$, N.S - Not significant (two-tailed Student's $t$ test) 
bioRxiv preprint doi: https://doi.org/10.1101/2021.10.05.463295; this version posted October 6, 2021. The copyright holder for this preprint (which was not certified by peer review) is the author/funder, who has granted bioRxiv a license to display the preprint in perpetuity. It is made available under aCC-BY-NC 4.0 International license.

792

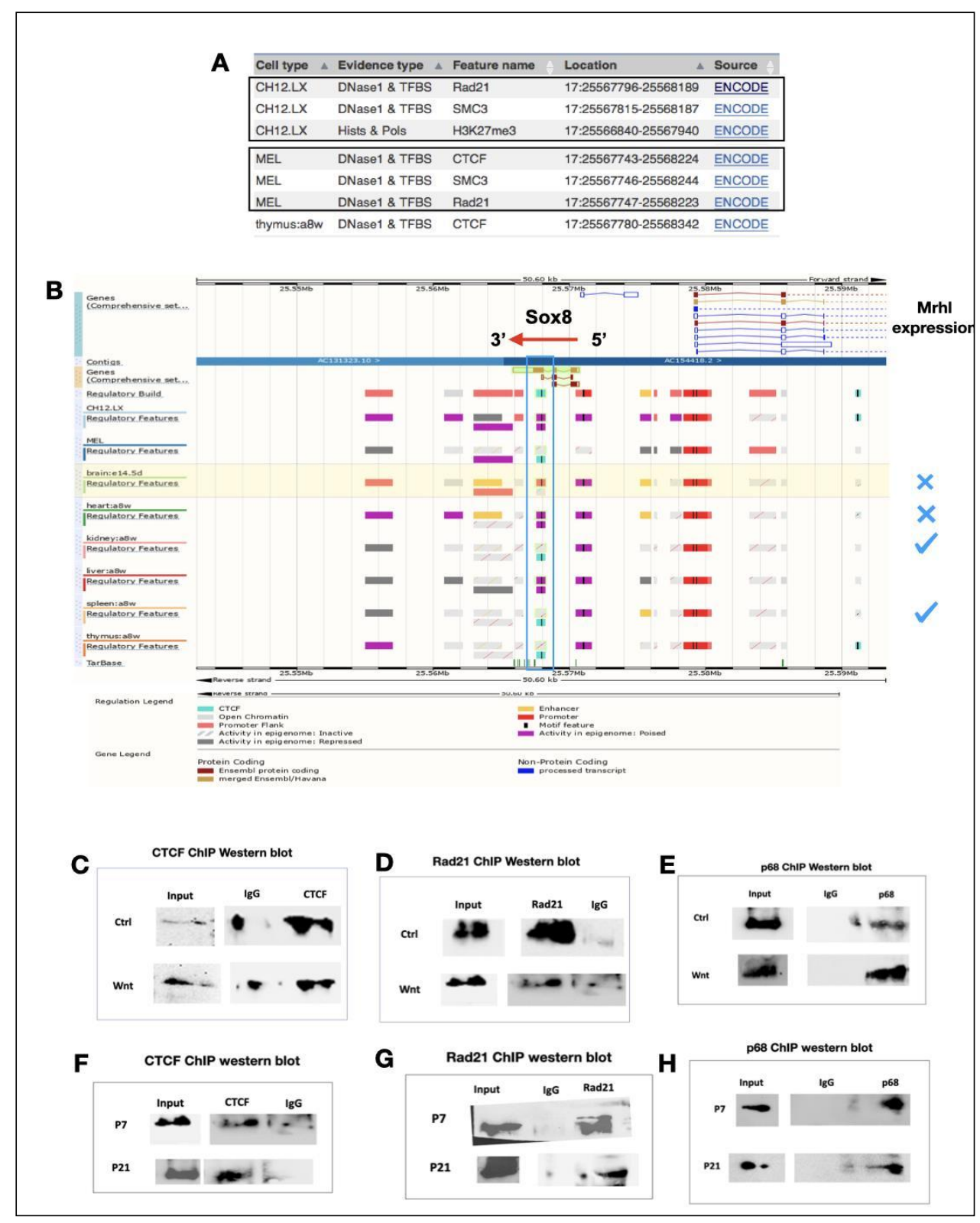

Fig. 4 supplementary: (A) Cohesin subunit SMC3 and Rad21 are found to bind close to the CTCF binding site in exon 3 of Sox8 (B) CTCF appears to be bound at the binding site within Sox8 in those tissue in which mrhl is expressed but not in some other in which mrhl isn't expressed (C) ChIP WB for CTCF in Gc1-spg cells with and without Wnt induction. (D) ChIP WB for Rad21 in Gc1-spg cells with and without Wnt induction (E) ChIP WB for p68 in Gc1-spg cells with and without Wnt induction (F) ChIP WB for CTCF in mice testes of ages 7 days and 21 days $(G)$ ChIP WB for Rad21 in mice testes of ages 7 days and 21 days (H) ChIP WB for p68 in mice testes of ages 7 days and 21 days 

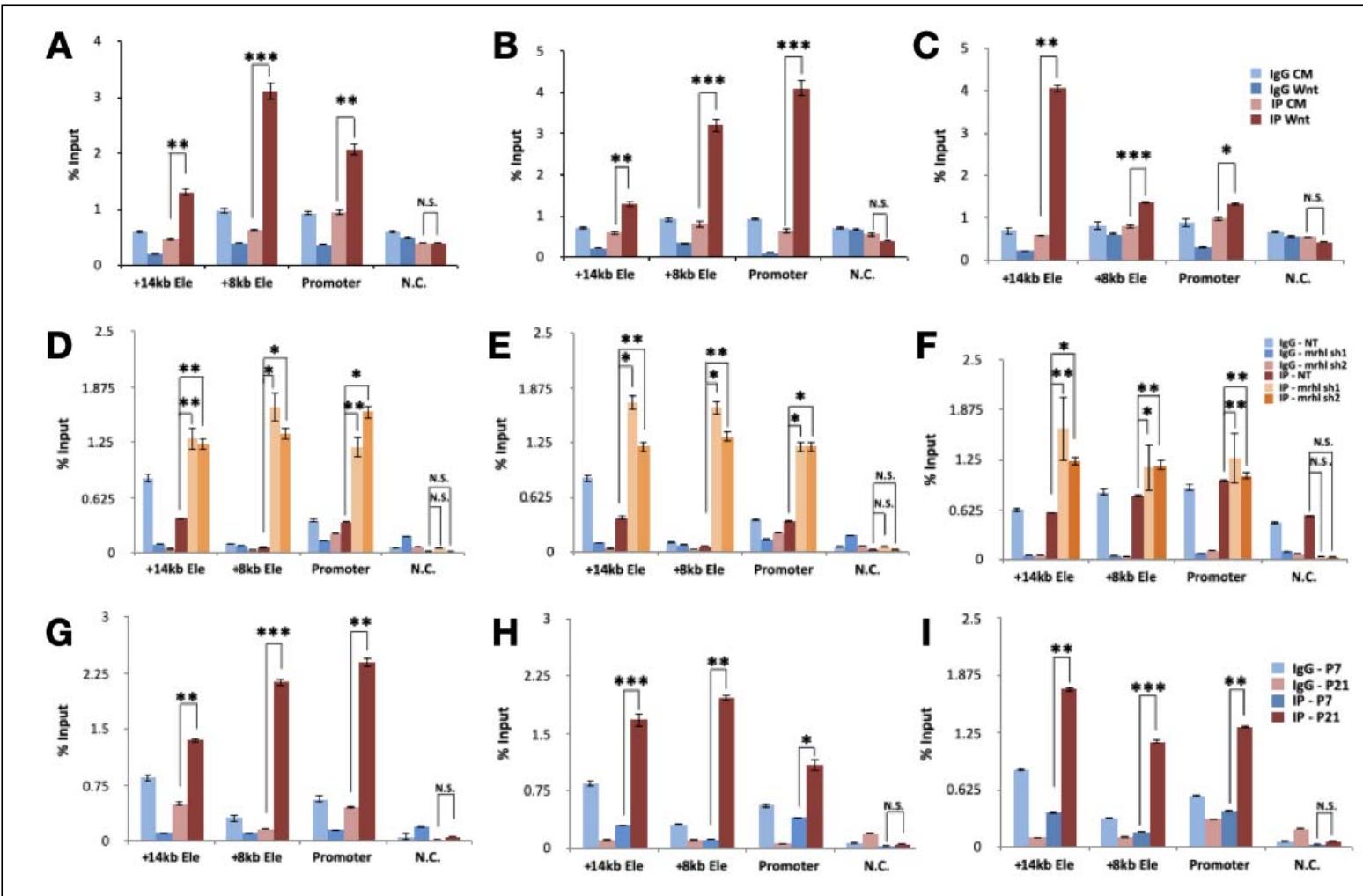

Fig 5: Enhancers at the Sox8 locus Results from ChIP-qPCR experiment for (A) H3K27ac (B) H3K4me1 and $(C)$ YY1 show a significant increase in the levels of this modification with Wnt signalling induced Sox 8 transcriptional activation at the promoter and both the enhancer elements. Results from ChIP-qPCR experiment for (D) H3K27ac, (E) H3K4me1 and (F) YY1 show a significant increase in the levels of this modification with Sox8 transcriptional activation at the promoter and both the enhancer elements in Mrhl knockdown cells when compared to cells expressing non-target control shRNA. Results from ChIP-qPCR experiment for (G) H3K27ac, (H) H3K4me1 and (I) YY1 show a significant increase in the levels of this modification in P21 mice testes when compared to P7 mice testes at the promoter and both the enhancer elements. Data in the graph has been plotted as mean \pm S.D. , N=3. ${ }^{* * *} P \leq 0.0005,{ }^{* *} P \leq 0.005,{ }^{*} P \leq$ 0.05, N.S - Not significant (two-tailed Student's t test) 
bioRxiv preprint doi: https://doi.org/10.1101/2021.10.05.463295; this version posted October 6, 2021. The copyright holder for this preprint (which was not certified by peer review) is the author/funder, who has granted bioRxiv a license to display the preprint in perpetuity. It is made available under aCC-BY-NC 4.0 International license.

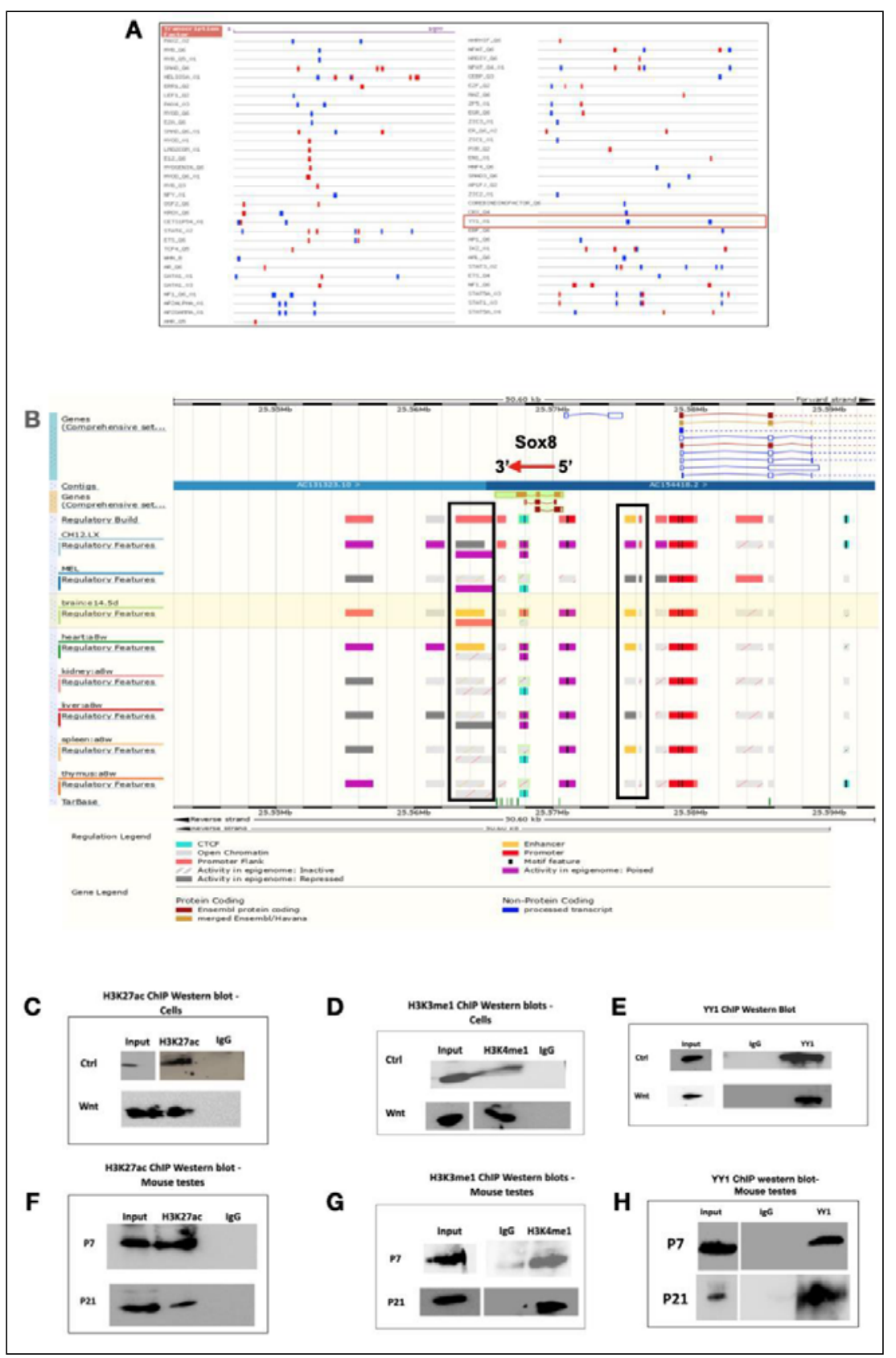

Supplementary figure 5: (A) Results from the Gene promoter miner tool to scan the promoter of Sox8 for presence of binding sites for transcription factors. YY1 has two binding sites in the promoter (highlighted with the red box). (B) The enhancer element present upstream and downstream of Sox 8 (highlighted with black boxes) show activity corresponding to transcriptional activity of the Sox8 gene. (C) ChIP western blot for H3K27ac in Gc1-spg cells with and without Wnt activation (D) ChIP western blot for H3K4mel in Gcl-spg cells with and without Wht activation (E) ChIP western blot for YYl in Gc1spg cells with and without Wht activation (F) ChIP western blot for H3K27ac in $P 7$ and P21 mice testes (G) ChIP western blot for H3K4me1 in P7 and P21 mice testes $(\boldsymbol{H})$ ChIP western blot for YY1 in P7 and P2I mice testes 


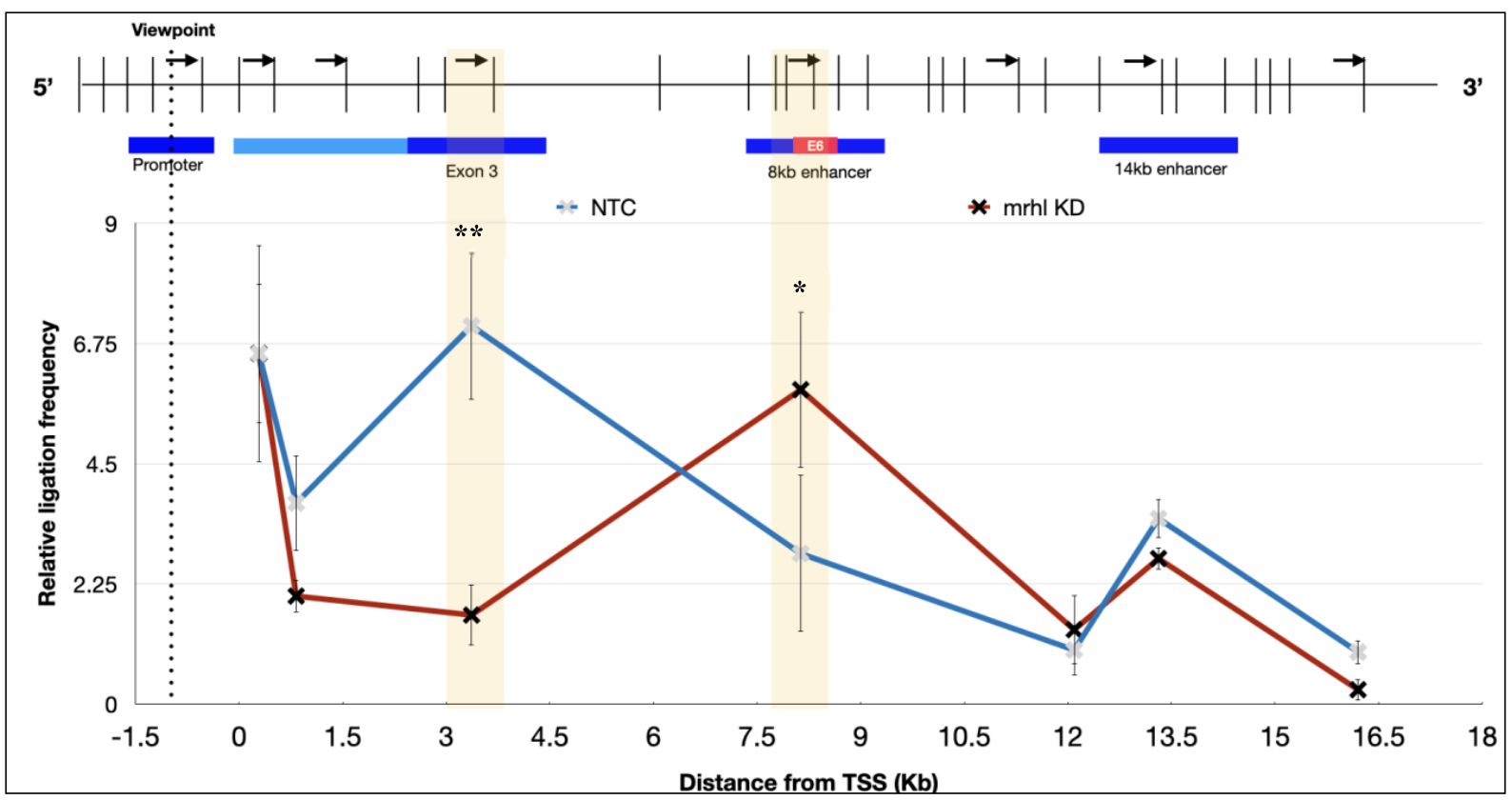

Fig 6: Chromatin looping at the Sox8 locus. 3C performed in Gc1-spg cells with non-target control shRNA (blue line) or Mrhl targeting shRNA (Red line). The schematic on top shows the positions of the DpnII sites (vertical bars) in the Sox8 locus relative to the genomic organisation. The black arrows indicate the $3 C$ primer binding sites and their directionality. The viewpoint primer is within the promoter of Sox8 (indicated with dotted line). Graphs has been plotted as the relative ligation frequency (Y-axis) as a function of the distance from TSS in $\mathrm{kb}$ (X-axis). In the control cells, a peak in the relative ligation frequency is observed between promoter and exon 3 (highlighted with shaded box). In Mrhl knockdown cells, the peak at exon 3 is no longer observed but a peak at enhancer $8 \mathrm{~kb}$ downstream of TSS (highlighted with shaded box) is observed indicative of interaction of the promoter with this segments of DNA. Data in the graph has been plotted as mean $\pm S . D$. , N=3. *** $P \leq 0.0005, * * P \leq 0.005, * P \leq 0.05, N . S-$ Not significant (two-tailed Student's t test) To knockdown mrhl, a pool of both shRNA were used and silencing of around 55\% was obtained while the host phkb gene expression level was not significantly perturbed. (B) Agarose gel image for DNA isolated from key steps of $3 C$ shows enrichment of DNA below $3 k b$ post restriction digestion with DpnII and an upward shift of the smear upon ligation 
803

804

805

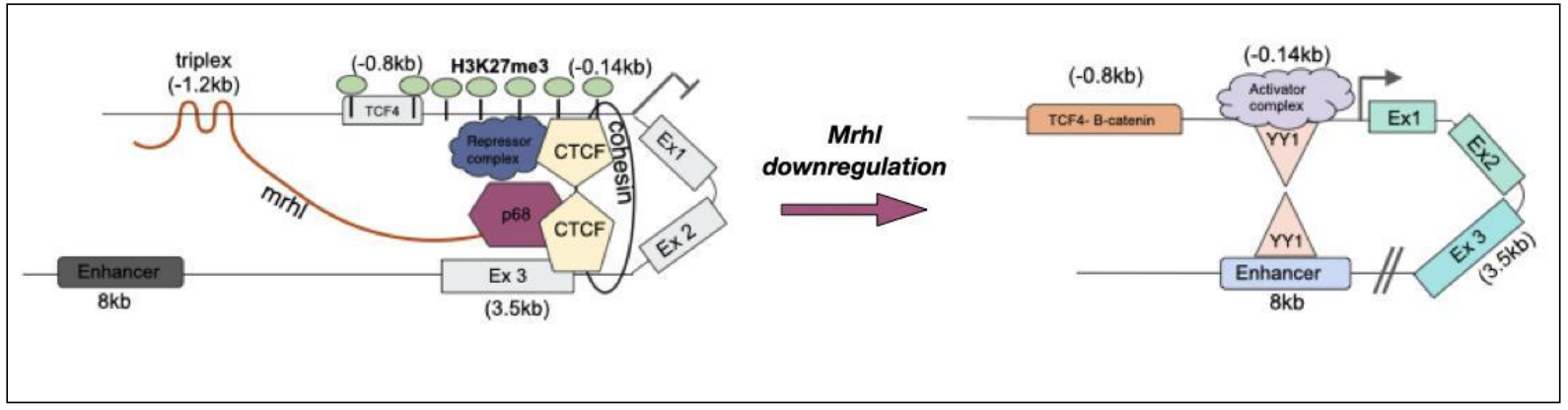

Fig 7: Model summarising the regulation of Sox8 in the B-type spermatogonial cells.

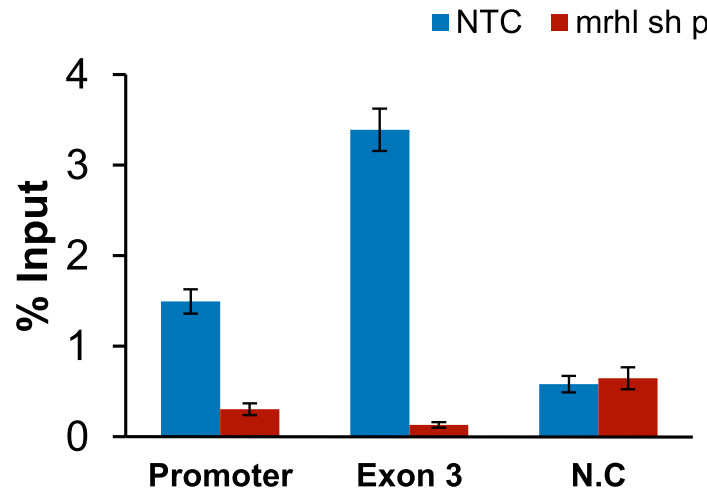

806 Supplementary figure 7: ChIP qPCR with CTCF specific antibody (no cross reactivity with CTCFL) shows the presence of CTCF at the Sox 8 locus in the presence of mrhl with a reduction in its occupancy upon mrhl downregulation. Graph has been plotted as mean. $N=3$. 